\title{
La eficiencia en el sistema penal español: con especial referencia al modelo de conformidades
}

\author{
Efficiency in the Spanish penal system: with special \\ reference to the plea bargaining model
}

\section{Claudio González Guarda ${ }^{1}$}

Universidad de Chile - Santiago, Chile

claudiogonzalez@iap.uchile.cl

https://orcid.org/0000-0002-1561-4641

\begin{abstract}
ResUMEN: El presente trabajo, describe el modo en que algunas lógicas eficientistas se han posicionado en el sistema penal español. Con este objetivo, se ha realizado una revisión sistemática de la literatura políticocriminal sobre la materia. Asimismo se han examinado las Circulares de la Fiscalía General del Estado, diversos informes sobre la Nueva Oficina Judicial (NOJ), estadísticas judiciales y los anteproyectos de códigos procesales penales (2011, 2013 y 2020), entre otras informaciones atinentes. De este modo determinamos tres ámbitos para observar este fenómeno: 1) en la literatura político-criminal respectiva; 2) en el intento de implementar un "gerencialismo orgánico" manifestado en la denominada Nueva Oficina Judicial; y 3) en el sistema de justicia negociada en España, especialmente en las conformidades. Concluimos que: a) A pesar de los escasos estudios sobre el gerencial/eficientismo en España, su penetración es indudable. Ciertamente de manera diferente a otros contextos (angloamericano y latinoamericano); b) La consolidación de un modelo eficientista de rasgos aceleracionistas de la justicia criminal se configura no solo debido a factores jurídicos, sino también a elementos socio-económicos, tecnológicos, y criminológicos; c) Su principal manifestación se observa en los procedimientos rápidos y en el modelo de conformidades (modo de terminar el litigio en el 70
\end{abstract}

1 Doctor en Derecho y Ciencias Sociales con mención en Derecho penal y Política criminal, de la Universidad de Málaga, España. Director del Centro de Estudios en Seguridad Ciudadana (CESC) del Instituto de Asuntos Públicos (INAP) de la Universidad de Chile. 
$\%$ de las causas ordinarias y en el $90 \%$ de los juicios rápidos); d) Los intentos de transformar toda la dimensión organizacional de la justicia penal no se han concretado.

Palabras Claves: Sistema de Justicia Penal; Eficiencia; Gerencialismo; Conformidad; Juicios Rápidos.

ABsTRACT: The present work describes the way in which some efficient logics have been positioned in the Spanish penal system. With this objective, a systematic review of the political-criminal literature on the matter has been carried out. Likewise, the instructions of the Attorney General's Office, various reports on the New Judicial Office (NOJ), judicial statistics and preliminary draft of criminal procedure codes (2011, 2012 and 2020), among other pertinent information, have been examined. In this way we determine three areas to observe this phenomenon. 1) In the respective political-criminal literature; 2) In the attempt to implement an "organic managerialism" manifested in the so-called New Judicial Office; and 3) In the justice system negotiated in Spain, especially in the plea bargaining model. We conclude that: a) Despite the few studies on management / efficiency in Spain, its penetration is undoubted. Certainly different from other contexts (Anglo-American and Latin-American); b) The consolidation of an efficient model of accelerationist features of criminal justice is configured not only by legal factors, but also by socio-economic, technological and criminological elements; c) Its main manifestation is observed in the rapid procedures and in the plea bargaining model (way of ending the litigation in $70 \%$ of ordinary cases and in $90 \%$ of rapid trials); $d$ ) The attempts to transform the entire organizational dimension of criminal justice have not materialized.

KEYWORDs: Criminal justice system; efficiency; managerialism; plea bargaining model; fast-tracks trials.

\section{INTRODUCCIÓN}

Aunque hay que tomar con cuidado la diferenciación entre modelos de justicia penal adversariales e inquisitivos (Langer, 2014; Armenta, 2015), se suele asociar el "eficientismo y gerencialismo"

2 Aunque no son lo mismo, en este artículo utilizamos gerencial y eficientismo como términos similares, pues ambos conceptos, finalmente apuntan a 
como un rasgo propio de los sistemas acusatorios o adversariales, y por tanto, con menor presencia en modelos con rémoras inquisitivas ${ }^{3}$. Si seguimos esta hipótesis, no serían extrapolables a España las experiencias ocurridas en modelos marcadamente pragmáticos, como los anglosajones (especialmente estadounidense), ni lo sucedido en las reformas procesales penales latinoamericanas de los últimos treinta años, acentuadamente adversariales. Desde nuestro punto de vista, basado en los argumentos que se expondrán en este artículo, esta hipótesis es errónea. ${ }^{4}$

Lo cierto es que en España el debate político-criminal está muy fragmentado, encontrando posturas que abogan por la incorporación de más eficiencia, mediante la construcción de un cuerpo gerencial en la justicia penal (Díez-Ripollés, 2012), hasta visiones críticas, que sostienen con preocupación, que algunas lógicas gerencial-eficientistas o actuariales, ya habrían sido internalizadas al sistema penal (Faraldo, 2008; Del Rosal Blasco, 2009b), otras miradas, si bien parten desde un marco crítico abogan

lo mismo, es decir, a dirigir la organización hacia criterios "resultadistas", relegando otros criterios valorativos y cualitativos.

3 Una de las principales rémoras inquisitivas del modelo español es la presencia de la "instrucción judicial" (Gascón, 2009), lo que implica la falta de autonomía del Ministerio Fiscal (Ministerio Público), tanto en términos orgánicos, como para investigar y ejercer la acción penal pública. De hecho, en todos los anteproyectos de los últimos 15 años se reconoce esto, proponiendo separar la actividad investigadora del órgano judicial de la de enjuiciamiento, eliminado los juzgados de instrucción o convirtiéndolos en juzgados de garantías. Otro país del entorno europeo que mantiene Juez Instructor es Francia, aunque desde el 2010 ha realizado diversas reformas, reforzando el rol de la Fiscalía.. Hitos relevantes han sido el Informe Léger (Villegas, 2010), y la Ley de Programación y Reforma de la Justicia 2018-2022.

4 Reformas gerenciales (New Public Management) son aquellas transformaciones del sistema público (justicia, salud o educación por ejemplo), que desde los años ochenta del siglo pasado, fomentan la instalación de un conjunto de herramientas provenientes de la gestión empresarial. Se denominan "gerenciales" pues derivan de una línea de políticas públicas denominada "Nueva gestión o Gerencia pública”. Entre otros objetivos pretende: achicar y liberalizar el Estado, incorporar indicadores para controlar la gestión, enfocar la organización hacia los resultados concretos, aligerar la burocracia estatal, propiciar el ingreso de nuevos sujetos provenientes del ámbito de la ingeniería y de las ciencias económicas, uso de la planificación estratégica, estandarización y protocolización de los sistemas, uso intenso de las TICs (González, 2018 y 2020). 
por la racionalización del gerencialismo (Brandariz, 2016). Realmente, a primera vista es complejo encontrar estos rasgos en el "sistema de justicia penal”, con excepción del modelo de conformidades, tal como lo veremos más adelante. Sin embargo, sí serían más notorias estas características en las reformas de la gestión del ámbito policial, en la criminalización de migrantes (Fernández y Brandariz, 2016), en el sistema penal juvenil, y en el sistema de prisiones, especialmente en el sistema de tabulación de riesgos (Rivera Beiras, 2015; Vila, 2013).

A lo anterior hay que agregar que la denominada "cuestión o crisis permanente procesal penal española” adiciona complejidad para analizar este asunto (Gascón, 2009; Gómez-Colomer, 2012;5 Fraga, 2018). La falta de un auténtico procedimiento acusatorio y la necesaria reforma a la dimensión organizacional del sistema de justicia penal ciertamente nos priva de un buen contexto para encuadrar los análisis respectivos. De todas maneras, en lo normativo sí han existido intentos de transformación, como los fallidos proyectos de nuevo código procesal penal de los años 2011 y año 2013, así como el actual Anteproyecto del $2020^{6}$. En el caso de las reformas organizacionales, si bien no ha existido un proyecto sistemático, sí se intentó poner en movimiento la denominada Nueva Oficina Judicial (NOJ) a la cual haremos referencia en párrafos más adelante.

Dada la naturaleza exploratoria de este trabajo, y para describir de mejor manera este proceso de gerencialización/eficientización, hemos seleccionado 3 rasgos o ámbitos que demostrarían la existencia de este fenómeno. Estos elementos son: 1) El rol de la literatura político-criminal en la descripción de este nuevo campo; 2) El intento de "gerencialismo

5 Este autor (Gómez Colomer, 2012: 21) propone para afrontar la crisis de la justicia española tres líneas de cambio: reformas orgánicas, reformas procedimentales, reformas a instituciones claves del proceso. Así como separar drásticamente el procedimiento de los asuntos complejos de aquellos de más fácil tramitación

6 En noviembre del 2020, el gobierno español presentó un nuevo proyecto para modificar la Ley de enjuiciamiento criminal (LECRIM), y avanzar hacia la instalación de un Código Procesal Penal de rasgos auténticamente acusatorios. Asimismo, se impulsa la creación de los Fiscales Constitucionales al objeto de adecuar la legislación española a las normas de la Unión Europea. Ver en: https://www.lamoncloa.gob.es/consejodeministros/Paginas/enlaces/241120-enlacejusticia.aspx 
orgánico", concretizado en la denominada "Nueva Oficina Judicial"; 3) La consolidación del modelo de juicios rápidos y conformidades. En la parte final presentaremos una serie de conclusiones que podrían resumirse en que, a pesar de que no se le ha dado la relevancia requerida al fenómeno del eficientismo/gerencialismo en el sistema penal español, su penetración es indudable ${ }^{8}$.

\section{1) LAS DIVERSAS POSICIONES EN LA LITERATURA POLÍTICO-CRIMINAL}

Para la literatura penal, criminológica y político criminal española (al igual que la latinoamericana por cierto), el gerencialismo, el eficientismo y el actuarialismo no son objetos usualmente observados; sin embargo, cuando se les considera se toma como referencia la literatura especialmente crítica realizada en el contexto angloamericano. Las referencias teóricas son explícitas en esta materia, especialmente la proveniente de la denominada teoría del riesgo (por ejemplo: Loader y Sparks, 2007; O’Malley, 2006; Garland, 2003 y 2005) y la específica que describe la filosofía actuarial (por ejemplo, Harcourt, 2007 y 2013). De este modo, se suele utilizar como marco teórico lo pregonado por la "nueva penología” y los estudios que sobre el gerencialismo y el actuarialismo comenzaron a fines de los 80 con Malcolm Feeley y Jonathan Simon (1988; 1992; 1994 y 2003). Estos estudios fueron realizados para el contexto estadounidense; sin embargo, con posterioridad han sido extrapolados a otras realidades político criminales, como a la propia España, como veremos a continuación.

7 El "gerencialismo orgánico" opera en oposición a la emergencia de un tipo de "gerencialismo inorgánico", que aflora desde las propias prácticas, rutinas, y actividades de los sujetos del sistema penal. Ejemplos de este tipo son todas las actividades de corte "auto-organizativos" que surgen en los sistemas penales, sin necesidad de protocolos, normas o reglamentos micro-organizacionales (González, 2018).

8 Ciertamente pueden existir otros ámbitos del sistema penal donde sería posible ver la penetración de estas lógicas gerenciales/eficientistas y actuariales, en especial las reformas en el ámbito policial (Domínguez y Rodríguez, 2003), donde se han incorporado una lógica de la Nueva Gestión Pública, como los sistemas de indicadores, metas, o incluso normas ISO (9000). Sin embargo, ese ámbito debe quedar fuera de este análisis pues requeriría una atención especializada para valorar su real impacto en las prácticas policiales. 
Para algunos autores, como Del Rosal Blasco (2009a: 35-41), la manifestación de este fenómeno en España es observable en la imbricación entre el actuarialismo penal, entendido como una nueva lógica penal que se centra más en los grupos que en los sujetos, y el gerencialismo, que es una línea de política pública específica derivada del New Public Management ${ }^{9}$. Por su parte Rivera Beiras (2015:136), desde una perspectiva crítica, refiere que las lógicas gerenciales (eficientismo) se internalizan en el sistema español por vía indirecta, mediante una forma de entender actuarialmente el sistema penal. Para este autor no hay duda de que este "paradigma actuarial" ya ha penetrado en el contexto hispano, especialmente en el sistema penal juvenil y en el penitenciario de adultos. Esto se reflejaría, en la forma en que es gestionado el concepto de "riesgo", específicamente en la denominada "estandarización" de los tratamientos y en el uso de las escalas predictivas al interior del sistema carcelario. Así, la incorporación del actuarialismo (gerencialismo) se insertaría dentro de un proceso punitivo más general, que no es otro que la intensificación del tránsito desde un derecho penal de hecho a uno de autor. Su crítica es enfática “...esa importación de modelos foráneos y extraños a la tradición constitucional en la que se inserta España, pese a haber sido resistida en ocasiones por sus propios aplicadores de base y otros operadores del sistema penal, ha penetrado fuertemente en el mismo" (Rivera Beiras, 2015).

Otros autores (Silva Sánchez, 2006, por ejemplo) también se han referido someramente al fenómeno del gerencialismo y al actuarialismo, pero especialmente a la eficiencia (Ortiz de Urbina, 2004, Ortiz de Urbina $\left.2003^{10}\right)$. A pesar de las dificultades para conceptualizarla se entiende

9 Para Del Rosal Blasco (2009a), ejemplos de esta situación serían la Ley de violencia de género del año 2004 y en ciertos delitos relativos a la seguridad vial. En ambos casos, el argumento sería más o menos similar: el Estado penaliza a un grupo de sujetos por pertenecer a cierto colectivo específico.

10 Este autor más que en el "gerencialismo" ha incursionado en el Análisis económico del derecho (AED) y en el actuarialismo. Este último concepto derivaría de la forma en que actúan las compañías de seguros cuando proceden a clasificar a sus asegurados en diferentes grupos según la probabilidad de riesgo que se les asigne. Así, el proceso de elaboración de categorías continúa hasta el momento en que los costes de elaboración de una nueva categoría superan los beneficios que se espera obtener con ella (Ortiz de Urbina, 2003: 49). Si bien el desarrollo del actuarialismo tiene un origen anglosajón, un fenómeno aproximado (pero no similar) habría ocurrido en la tradición penal 
que se actúa eficientemente cuando (a) con los medios de los que se dispone se satisface la máxima cantidad de fines, o alternativamente, cuando (b) se obtiene un o unos fines con el menor costo posible; en esta ocasión, se tasan los fines y se minimizan los medios precisos para conseguirlos (Ortiz de Urbina, 2004: 44). En el caso de Silva-Sánchez (2006: 74), se aproxima al gerencialismo (aunque no lo conceptualiza) ${ }^{11}$ ya que lo considera como uno de los factores "colaterales" que incidiría en la "expansión del Derecho penal" contemporáneo ${ }^{12}$. El gerencialismo sería así un "modo ejecutivo" de gestionar el sistema penal, lo que se vería favorecido por la idea de que las actuales cuestiones de eficacia de la seguridad pública son mejor comprendidas como un "asunto de gestión penal”. Las críticas de Silva Sánchez (2006) se centran sobre todo en la "justicia negociada" y en instituciones como "las conformidades", argumentando que su implementación sin resguardos abre el camino a la mera informalidad en la solución de las contingencias (colapso de los tribunales y urgencias político-criminales). Para Silva Sánchez, el Derecho penal quedaría reducido así a una "facticidad administrativoejecutiva". Esta tesis, aunque postulada desde el derecho penal sustantivo, podría aproximarse a la idea de "administrativización del sistema penal" (Langer, 2019).

Como es observable, la perspectiva con la que Silva Sánchez (2006) aborda este punto es de carácter sistémica, referida a fuerzas

continental europea a través de la doctrina alemana del Derecho penal orientado a la eficacia/eficiencia (orientado a las consecuencias), especialmente mediante los trabajos de la Escuela de Frankfurt (Ortiz de Urbina, 2003: 51).

11 Efectivamente el autor no ofrece un concepto, al menos operativo, de lo que él entiende por gerencialismo, ni tampoco utiliza la literatura que en ese momento existía en el contexto anglosajón sobre New Public Management. Sin embargo, hace suyas las inquietudes que sobre este asunto que ya habrían indicado genéricamente Hassemer y Muñoz Conde (1989).

12 La reconocida tesis de este autor en esencia indica que existe una innegable tendencia en la legislación penal actual hacia una ampliación (expansión) de los tipos penales y una agravación de los ya existentes, así como una reinterpretación de las garantías clásicas del derecho penal sustantivo y del procesal penal, creando nuevos bienes jurídico-penales, ampliando los espacios de riesgo jurídico-penalmente relevantes, flexibilizando las reglas de imputación y relativizando los principios político-criminales de garantía (Silva Sánchez, 2006:4-5). 
generales que transforman el sistema penal. Sin embargo, en otro trabajo (Silva Sánchez, 1996), enfocado esta vez en la eficiencia y el Derecho penal, el autor aborda la eficiencia más bien como un "asunto personal", es decir, los cálculos que el sujeto hace entre su "posible" trasgresión y la reacción del sistema penal ${ }^{13}$. Esta distinción es relevante, pues muchas de las aproximaciones a la eficiencia penal se hacen desde los análisis económicos del derecho (AED), es decir, con un marcado acento en la eficiencia personal, y no tanto sistémica u organizacional (Ortiz de Urbina, 2004). A pesar de lo relevante que resulta comprender la eficiencia personal, será finalmente la "eficiencia penal sistémica" la que nos hará entender a la eficiencia inserta en la organización (la eficiencia organizacional) "justicia penal”.

Otra perspectiva, que podríamos denominar "realista”, pone de relieve la necesidad de instalar un nuevo modelo organizacional en el sistema de justicia penal español (Díez-Ripollés, 2012) o racionalizar el gerencialismo (Brandariz, 2016). Esta visión aboga por una "visión optimista” del gerencialismo, es más, sugiere su instalación como una manera de modernizar el sistema de enjuiciamiento español, alejándolo de las tentaciones de manipulación por la clase política, en otras palabras, impulsa una especie de independencia judicial vía gerencial. Pero para Díez-Ripollés las ventajas no solo serían político-judiciales, sino también técnicas, debido a que la conveniente creación de un "cuerpo gerencial" no judicial (realmente no jurídico, pues puede ser organizacional pero judicial) especializaría el manejo de las funciones administrativas, y de otras actividades ligadas a la gestión de salas de gobierno, presidencias, decanatos de juntas de jueces. En el fondo, se construiría un cuerpo

13 Aunque existen muchas formas de comprender la elección racional, un modo simple es entender que esos cálculos que hace el sujeto son racionales, en el sentido que intentan ampliar al máximo su bienestar dentro de las limitaciones en que se mueven; limitaciones de información, capacidad de toma de decisiones, conflicto con otros valores, etc. Esa racionalidad les lleva a responder de forma diferente en función de los estímulos, o incentivos, presentes en cada caso. Y esos incentivos pueden ser modificados por la política jurídica. De modo que los individuos cometen actos ilícitos...los cometen porque los beneficios que obtienen de su comisión son mayores que los costes, siendo beneficios y costes magnitudes de la más diversa índole (monetaria o no) (Pastor, 1989:169). 
gerencial que desarrollaría las imprescindibles buenas prácticas de un servicio público como es la administración de justicia y que requiere urgente modernización (Díez-Ripollés, 2012: 52).

Lo cierto es que la tendencia "realista" va en línea con lo que autores de otros contextos han asumido sobre esta materia. Por ejemplo, Freiberg (2005), en Australia, plantea limitar la influencia del "managerialism", pero al mismo tiempo reclama la necesidad de fortalecer la gestión moderna del sistema de justicia penal y mejorar sus servicios, es decir, más y mejor gestión judicial. El atemperamiento de las críticas al "gerencialismo penal" finalmente lo que hace es reconocer al sistema penal como un modelo de prestación de servicios, que, por tanto, debe ser eficiente y de calidad. Ciertamente sería absurdo pensar en crear una organización para que sea ineficiente. El problema pareciera ser que la literatura no tiene claro qué significa realmente "eficiencia ni calidad" de la justicia penal, y se hacen aproximaciones, o muy teóricas (maximalistas) o muy cuantitativas (reduccionistas), y de esa raíz seguramente nacen muchos de los posicionamientos contradictorios (González, 2018). Probablemente, por estas incertezas es por lo que autores como Brandariz (2016) indican que el gerencialismo penal es un paradigma internacional que configura las políticas del castigo contemporáneas, escapando así a simples lógicas locales. Este autor argumenta que parte del atraso de su estudio en España se ligaría, entre otras razones, a la desactualización española del modelo acusatorio, y, probablemente, a la larga sombra de la justicia franquista. Este rasgo sería clave en la permanencia de un modelo de fuerte raigambre inquisitiva y con "injertos" de corte adversarial.

En síntesis, para bastante literatura político-criminal parece evidente que el gerencial/eficientismo sí se está posicionando en el sistema de justicia penal español, pero probablemente de un modo diferente a lo que ocurre en otros contextos ${ }^{14}$. Trabajos como los de Brandariz,

14 Una de las razones para esta diferencia tiene que ver con la resistencia cultural (veto cultural) a los modelos de justicia penal provenientes de otros contextos, especialmente anglosajones. Por ello, si bien se aceptan ciertas instituciones "acusatorias", estas son fuertemente restringidas, por ejemplo, "el principio de oportunidad reglado", la misma situación se produciría en el Sistema de Justicia Penal francés (Carvajal, 2010). Sin embargo, otros autores afirman que la "americanización" del modelo español ya es un hecho (Ferré, 2018). 
Rivera Beiras, Fernández, Silva Sánchez o Del Rosal darían cuenta de una tendencia gerencial "negativa" en el campo judicial y penitenciario, especialmente en la configuración de un modelo actuarial para la medición, predicción y valoración del riesgo penal (Vila, 2013; Martínez, 2014; Pueyo y Redondo, 2007); similares lógicas gerenciales habrían sido incorporadas en el ámbito policial (Domínguez y Rodríguez, 2003) o en la denominada crimigración (Fernández y Brandariz, 2016). Por otra parte, trabajos como los de Díez-Ripollés (2012) o de modo aproximado el de Brandariz (2016), optarían por una visión realista de esta tensión entre eficiencia y justicia criminal, posición especialmente fundada en la indudable naturaleza de servicio público de la administración de justicia penal. En todo caso, lo cierto es que la escasez de investigaciones en esta área son el principal inconveniente para profundizar en los análisis de este tipo.

\section{2) El intento de un "gerencialismo orgánico" en la justicia penal española: La Nueva Oficina Judicial (NOJ).}

Tradicionalmente se ha criticado la dimensión organizacional del sistema de justicia español, debido a que no ha estructurado un modelo coherente y moderno de administración de justicia (Pastor, 2003). Sin embargo, a partir del diagnóstico hecho en el "Libro Blanco" de la justicia de España, elaborado por el Consejo General del Poder Judicial (CGPJ) en 1997 y del Pacto de Estado para la reforma de la justicia del año 2001, esta situación se ha intentado remediar. ${ }^{15}$

Algunas de las críticas usuales al sistema son no constituir una justicia eficiente, ágil y oportuna. Así, la Oficina Judicial que ha regido en España se ha caracterizado por los siguientes rasgos negativos: 1. Dispersión, existiendo tantas oficinas judiciales como órganos unipersonales y colegiados, lo que impide la utilización de economías de escala y alcance; 2. Infrautilización de capacidades y aptitudes profesionales de los secretarios judiciales (ahora letrados de la administración de justicia); 3. Indefinición de funciones y de carrera profesional de los diferentes cuerpos al servicio de la administración de justicia; 4 . Inexistencia de

15 Disponible en: http://www.oas.org/juridico/spanish/mesicic2_pan_anexo_25_sp.pdf. Acceso en 16 mayo 2021. 
métodos de trabajo racionales y homogéneos; 5. Inmuebles dispersos y espacios utilizados indebidamente; 6 . Desarrollo de tecnologías en cada una de las administraciones responsables con problemas de compatibilidad e infrautilización de las mismas; 7. Inexistencia de control eficiente e inexistencia de accountability; 8. Capacidad productiva condicionada a la capacidad resolutiva de jueces y magistrados (Boletín de Información año LXIV, Ministerio del Interior, 2010) ${ }^{16}$.

Los intentos de reforma han sido acompañados por una nutrida batería normativa, comenzando con la modificación de la Ley Orgánica del Poder Judicial del año 2003 (vigente desde enero de 2004), seguida en el año 2005 por el reglamento orgánico del cuerpo de secretarios judiciales y en el año 2007 se crea la comisión de implantación de la Nueva Oficina Judicial (NOJ) encargada de poner en marcha estas reformas a través de diversos grupos técnicos desplegados en el territorio. Otro hito relevante, es la presentación por parte del Ministerio de Justicia en el año 2009 del "Plan estratégico de modernización del sistema justicia 2009-2012"17, donde se reimpulsaba este proceso de reingeniería del sistema de justicia español. Todo lo anterior se consolidó a través del Plan de Acción 20122015 de la Secretaría General de la Administración de Justicia

En términos generales la NOJ pretendía crear dos secciones o ámbitos de trabajo, por una parte, las Unidades procesales de apoyo directo (UPAD) y, por otro lado, los denominados Servicios comunes procesales (SCP). Las primeras tendrían por objeto dar apoyo inmediato a las funciones judiciales más cercanas a los niveles de toma de decisiones netamente jurisdiccionales. Las segundas deberían desembocar en las llamadas “macroficinas judiciales”, encargadas de una serie de actuaciones,

16 Sin perjuicio de lo anterior, se puede observar información actualizada sobre estas temáticas en: https://www.poderjudicial.es/cgpj/es/Temas/Estadistica-Judicial/Estadistica-por-temas/Estructura-judicial-y-recursos-humanos--en-la-administracion-de-justicia. /

17 El uso de un Plan Estratégico en el sector Justicia es en sí mismo un giro organizacional. Las planificaciones de este tipo son usuales en el ámbito privado, y han calado en los últimos años en distintos sectores públicos. En Iberoamérica las Cumbres Judiciales (Latinoamérica más España y Portugal) han propiciado la creación de un modelo estandarizado de Planificación Estratégica para las entidades del sector judicial. Más información en: http://www.cumbrejudicial.org/web/guest/antecedentes. 
no necesariamente jurisdiccionales, tales como notificaciones, embargos, citaciones, etc. (Martínez, 2010; Rayón, 2007).

Tradicionalmente el enfoque de la transformación de la gestión ha estado centrado en el "atraso judicial"18. De hecho, el Consejo de Europa sugería desde hace bastante tiempo "sacar del sistema todos los elementos no estrictamente judiciales". Lo cierto es que, a pesar de lo relevante que es combatir el "atraso judicial”, esta visión no basta, pues no observa sistémicamente la gestión judicial. A este modo incompleto de ver los cambios organizacionales, le basta, con la incorporación de nuevas herramientas informáticas (TICS), y lo vemos plasmado en proyectos como la Agenda Digital 2000 y el plan plurianual 2014-2018, relativo a la justicia en red europea ${ }^{19}$ o también denominado proyecto E-Justice (Garrido et al, 2015) ${ }^{20}$.

Dentro de los elementos más destacables de este proceso organizacional de la justicia española podemos resumir los siguientes puntos ${ }^{21}$ :

1. En un proceso de casi 15 años, desde los primeros acuerdos políticos para la transformación de la justicia (2002/2003), una cantidad no desdeñable de regulaciones se han dictado sobre la materia. Sin embargo, esto no se ha visto reflejado en la práctica, al menos de la manera que

18 Alusión indirecta al fenómeno de la masificación de casos del sistema penal.

19 Si bien no existe una norma vinculante ni un tratado marco para los países que componen la Unión Europea, sí existen una serie de recomendaciones en el campo de la gestión judicial que normalmente son asumidas por los distintos países y seguidas con ciertos matices por cada uno de ellos. Un organismo con una alta influencia en estas políticas es el European Commission for the Efficency of Justice (CEPEJ) http://www.coe.int/T/dghl/cooperation/ cepej/default_en.asp.

20 En España el proyecto informático más relevante es LEXNET que busca la interconexión entre todas los servicios judiciales y la digitalización completa y el abandono del expediente como "centro del proceso", el cual se ha iniciado el año 2016 y se espera que esté finalizado dentro de un período corto de tiempo.

21 Alguna de estas informaciones ha sido recabada de un trabajo exploratorio o sondeo en el sistema de justicia penal español, cuyo objeto era desarrollar una etnografía judicial más concreta en el año 2020, la cual no se consumó debido a la emergencia sanitaria, pero que se espera retomar en el futuro. De este modo se ha conversado con diversos operadores del sistema de justicia penal español, quienes han indicado algunos de estos antecedentes. 
se esperaba. Algunos factores que han entorpecido esto son: a) La crisis económica del año 2008 en adelante y las restricciones presupuestarias respectivas; b) La falta de consenso político, lo cual se refleja en que aún no hay un nuevo Código de enjuiciamiento criminal; c) La falta de adecuación de las infraestructuras (macro-oficinas judiciales); d) Las resistencias organizacionales propias de cualquier reforma de este estilo y que ocurren en cualquier realidad político-criminal, materializadas en el corporativismo judicial y en el recelo de gremios funcionariales a perder cuotas de poder; e) Aunque es discutible, la negativa influencia de la estructura de "autonomías regionales" que impiden la unificación de criterios e iniciativas transformadoras en las reformas judiciales. ${ }^{22}$

2. La reforma en términos prácticos se ha enfocado más que un cambio del modelo cultural de organización de la justicia o una reforma gerencial propiamente tal, en una modificación del funcionamiento de los despachos judiciales. Así, bajo la hipótesis de que existían recursos ociosos (especialmente de personal administrativo) en el sistema de justicia, se ha intentado maximizar el provecho de ellos a través de un proceso de "limpieza de la burocracia de los procedimientos". Sin embargo, no se ha contratado personal nuevo, ni se ha apostado explícitamente por una nueva planta de funcionarios de menor edad o con formación en ciencias económicas, industriales o de gestión, lo cual le imprimiría evidentemente un sello y estilo realmente gerencial. ${ }^{23}$

Lo cierto es que el pretendido proceso de transformación no ha cambiado considerablemente la conformación de equipos de trabajo en

22 Los planes pilotos de la Nueva Oficina Judicial esencialmente se han puesto en marcha en algunos tribunales de algunas comunidades autónomas del norte de España, especialmente la ciudad de Burgos y el País Vasco; también es relevante destacar que algunas comunidades tienen la competencia de justicia transferida (Galicia, Andalucía, País Vasco y Cataluña) lo cual dificulta la uniformidad en esos procesos y depende mucho de los recursos propios que tenga la propia comunidad autónoma y en definitiva de un tema de iniciativa política.

23 No se han incorporado de manera masiva e intensa dos elementos claves para cualquier transformación gerencial. Uno, ciertamente, el reclutamiento de profesionales del campo de la economía, administración de empresas, ingeniería o políticas públicas. Y otro, la incorporación de herramientas de control de la gestión (cuadro de mando integral por ejemplo), sino ocurre esto, se corre el riesgo de confundir una gestión "contable" del sistema con una gestión organizacional más compleja. 
los tribunales. Sin perjuicio de lo anterior, se ha pasado de macro equipos de trabajo en los juzgados de instrucción a un formato más comprimido. Hoy existen, aunque no en términos totalmente estandarizados una configuración diferente de cada tribunal penal, constituido por un Juez Instructor, independiente jurisdiccionalmente y orgánicamente dependiente del Consejo General del Poder Judicial; un Juez Letrado (se trata de un juez letrado de la administración de la justicia que no es juez) que en los hechos es un "coordinador organizacional" (dependiente del Ministerio de justicia), cinco funcionarios tramitadores, tres gestores y dos funcionarios o auxiliares judiciales (todos dependientes de la comunidad autónoma respectiva). En otras palabras, un formato más estrecho y operativo, esto estaría conformado por un juez letrado, dos gestores y dos tramitadores, el recurso humano no utilizado ha sido reenviado a la macro-oficina citada anteriormente.

3. Como hemos indicado, esta reforma apuntaba a todos los ámbitos en la justicia. Ahora bien, en el campo estrictamente penal, para que exista armonización entre lo organizacional y lo normativo, sería esencial que exista una modificación del modelo de enjuiciamiento propiamente tal. Es decir, pasar de un sistema que mezcla lo inquisitivo y lo acusatorio, a un modelo acusatorio depurado. Esto, aunque sea un cambio legal, permitiría organizar de mejor modo los procesos de trabajo propios de la cultura del management court.

4. Dentro de los factores positivos que favorecen una reforma organizacional en la justicia española (un giro gerencial), está el hecho de ser uno de los países occidentales con menor conflictividad, así, un bajo volumen de delitos puede ser razonablemente absorbido y gestionado por su sistema de justicia ${ }^{24}$. Lo anterior, marca una diferencia notable con lo que sucede en la mayoría de los países latinoamericanos, especialmente

24 En general, muchos informes indican que las cifras delictuales en España no son elevadas, esto ocurre tanto si lo comparamos en el contexto europeo, y mucho más si lo comparamos en el ámbito occidental (García, 2019: 102103). En todo caso una disminución de los asuntos tramitados por el sistema y en paralelo con una mejora en las capacidades organizacionales del sistema no necesariamente se reflejaran en una mejora de la performance jurisdiccional. Como se verá más adelante en la propia España a pesar de una disminución en la sobrecarga de trabajo del sistema penal, esto no ha trasmitido hacia la calidad del sistema. 
cuando tratamos de comprender las reformas gerenciales dentro de un contexto de "masificación de casos".

Por ello, cuando se hable de "la cuestión procesal-penal española", muchos de los dardos apuntan más bien a la existencia de atrasos judiciales significativos, comparativamente evaluados con otros países de su entorno, así lo han determinado los informes del Centro Europeo por la Eficiencia en la Justicia (CEPEJ) (Alonso Cuevillas, 2015). Otros sin embargo, afirman que no existiría una diferencia significativa en términos de atrasos e indicadores judiciales respecto de otros países occidentales (García et al, 2013) ${ }^{25}$.

En síntesis, si bien los procesos de reforma en el ámbito en la justicia penal son lentos (tanto los organizacionales como los normativos), caracterizándose más bien como incrementales, su dilación puede provocar un sistema inorgánico y con ineficiencia endémica. En todo caso, es verdad que cada vez menos jueces asumen funciones organizacionales, además, se han mejorado las estadísticas judiciales y las Inspecciones Judiciales. Otro factor positivo, es que si bien, el Ministerio Público aún está a la sombra del Juez de Instrucción, la Fiscalía ha ido adquiriendo cierta libertad para su gestión y esencialmente se ha profundizado su informatización. Por tanto, en asuntos de delincuencia clásica no pareciera haber una afectación de garantías penales tan directa y extremadamente grave por los problemas de gestión (aún a pesar del atraso judicial).

Sin embargo, el problema de "ineficiencia endémica", eventualmente puede afectar el procesamiento de delincuencia más compleja (delitos de corrupción, por ejemplo). De hecho, cuando en las dos primeras décadas del siglo emergieron una seguidilla de casos de corrupción político-empresarial, los problemas organizacionales de la justicia penal fueron ostensibles, especialmente en el ámbito de la

25 Pareciera que estas diferencias de opiniones se darían por incongruencia en los datos. Se supone que las Estadísticas Judiciales son llevadas por el Consejo General del Poder Judicial, especialmente los informes anuales (desde el 2003) como el Informe denominado "Dato a Dato", que se refiere, entre otros asuntos a medios, cargas de trabajo, duración de procedimientos. Sin embargo, estos datos no cuadran con los que aparecen informados en el CEPEJ y que en principio son proporcionados al organismo europeo por las propias autoridades españolas (Alonso Cuevillas, 2015: 44-45). 
denominada "corrupción urbanística y la financiación ilegal de los partidos políticos, lo que dio lugar a los “macro-procesos"26. En ese contexto, las deficiencias organizacionales del sistema inicialmente perjudicaron el éxito de las investigaciones. Especialmente, por la dificultad para conformar equipos de trabajo (tándem policía-fiscalía), enervando así la necesaria celeridad ante la potencial desaparición de pruebas e imposición de medidas cautelares urgentes, así como, trabando la "especialización” de las unidades investigativas y poniendo en cuestión la autonomía real de la Fiscalía, entre otros problemas ${ }^{27}$. Estas dificultades demostraron, que al menos en los delitos complejos, se requiere un dibujo organizacional diferente al existente.

\section{3) Juicios Rápidos y Justicia Negociada en España. Las Conformidades.}

Para comprender los juicios rápidos y la justicia negociada desde una perspectiva político-criminal, debemos observar el fenómeno desde 3 puntos de vista: 3.1) La expresión cuantitativa de las conformidades y juicios rápidos en el sistema de justicia penal español; 3.2) La naturaleza del frondoso sistema de conformidades; y 3.3) Argumentos a favor y en contra del modelo de juicios o procedimientos rápidos ${ }^{28}$.

${ }^{26}$ Algunos de los "macro-procesos" más relevantes y conocidos son por ejemplo el caso "Ballena Blanca", el caso "Malaya", el caso Gürtel, el caso Nóos, el caso de los ERE de Andalucía, El caso Puyol, y el Caso Brugal entre una decena de otros casos de corrupción urbanística.

Lo cierto es que muchos de estos problemas tienen un margen de mejora, especialmente mediante las exigencias que introduce la "europeización del proceso penal”. Esto se realiza mediante la trasposición de las Decisiones Marco europeas a las legislaciones internas a la justicia penal. Las áreas que han ocupado mayor atención se refieren a la delincuencia transfronteriza y al crimen organizado, por ejemplo: orden europea de detención y entrega, equipos conjuntos de investigación, decomiso de bienes, intercambio de información de antecedentes penales, entre otras (Gascón, 2009). Del mismo tenor es el Reglamento (UE) 2018/1805 del Parlamento Europeo y del Consejo que regula el reconocimiento mutuo de las resoluciones de embargo y decomiso.

Los juicios rápidos estuvieron presentes en el Pacto de Estado para la Reforma de la Justicia del 2001 y en los diversos Anteproyectos de CPP. Dicho pacto - suscrito entre el Partido Popular (PP) y Partido Socialista Obrero 


\section{1) LA EXPRESIÓN CUANTITATIVA DE LAS CONFORMIDADES Y JUICIOS RÁPIDOS EN EL SISTEMA DE JUSTICIA PENAL ESPAÑOL.}

A pesar de que es complejo establecer una estadística específica acerca de qué porcentaje de resoluciones penales se realizan vía conformidad, se estima que corresponden en torno al 70\% de los casos resueltos en los tribunales penales, y en los juicios rápidos esta cifra rondaría el $90 \%$ de las soluciones ${ }^{29}$. El mayor inconveniente para establecer su número exacto es la dispersión de las conformidades en diferentes tipos de procedimientos en el sistema de justicia español (Fraga, 2018; Ferré, 2018), por lo mismo, la mayoría de los trabajos de referencia sobre esta materia no aportan datos concretos, sin embargo, concuerdan en su alta incidencia ${ }^{30}$.

La paradoja es que la alta incidencia de las conformidades se ha dado en un contexto caracterizado por el descenso de asuntos judiciales en la jurisdicción española. Aunque esta declinación ya se constataba desde el 2009, fue catalizada por la impresionante caída de casos penales desde el año 2015 (Figura No 1 . Sin embargo, también es observable que luego de la abrupta caída del período interanual 2015-2016 la tendencia

Español (PSOE) - en dos puntos hace referencia explícita a los procedimientos rápidos. En el 17, indica que en una nueva LECRIM, uno de sus principales objetivos será "La agilización de los procedimientos, la mejora de los procedimientos abreviados, el enjuiciamiento inmediato de los delitos menos graves y flagrantes, y la simplificación de trámites en las grandes causas”. En el 19, se hace mención explícita "a la atención a la agilización y rapidez de la Justicia”. Ver texto completo en: http://www.juecesdemocracia.es/pdf/ pactoRefJust.pdf.

29 Según Gaddi (2020:1004) "Las sentencias por conformidad representan la solución más frecuente de los procesos penales en España. Se calcula que alrededor de un $70 \%$ de las sentencias emitidas en el 2018 , tanto condenatorias como absolutorias, fueron en conformidad con la posición del Fiscal... En los juicios rápidos, las conformidades han llegado en 2018 a representar el $90 \%$ de las sentencias condenatorias”. García Magna (2019: 109), indica que en año 2011, las cifras oficiales referían que el porcentaje de conformidades en el procedimiento abreviado se movían entre el 48\% y 68\%, luego de 10 años, ya sabemos que el dato actualizado las sitúa en el $70 \%$ o más.

30 En todo caso, cada vez se cuenta con mejores estadísticas tanto del Consejo General del Poder Judicial como de las Memorias de la Fiscalía General del Estado (MFGE). 
descendente pareciera ralentizarse, contemplándose un leve aumento al menos hasta las cifras del año 2019.

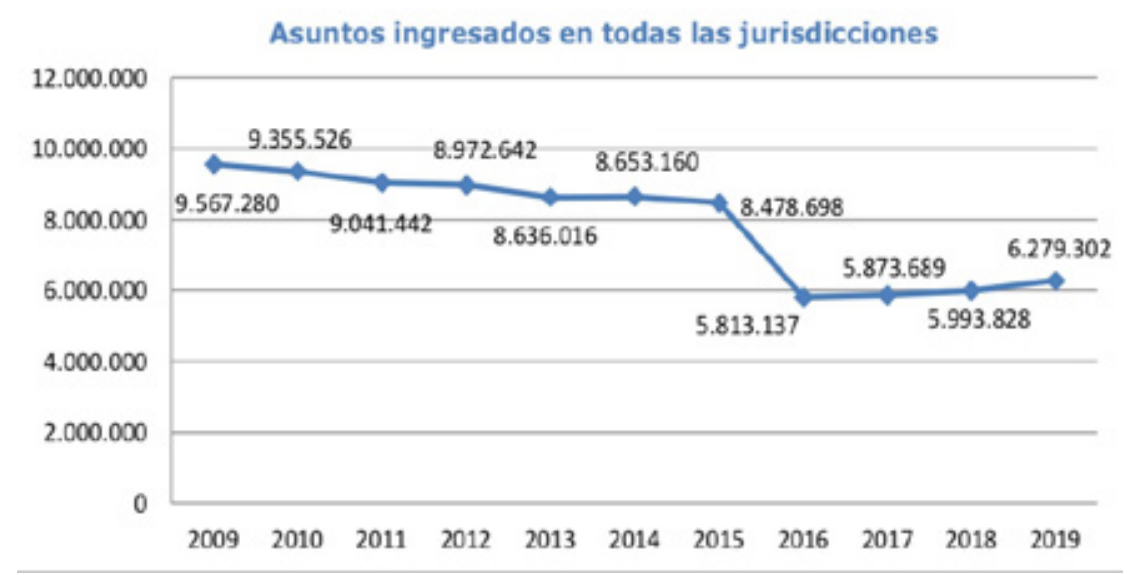

Figura 1. Asuntos ingresados en todas las jurisdicciones desde el 2009.

Fuente: Informe Dato a Dato del Consejo General del Poder Judicial del 2019.

Las razones que explican esta caída ciertamente se relacionan con la puesta en marcha de una serie de cambios legislativos ${ }^{31}$, en especial la Ley 41/2015 de 5 de octubre, que modificó la Ley de Enjuiciamiento Criminal para la agilización de la justicia penal y el fortalecimiento de las garantías procesales ${ }^{32}$. Esto produjo un desplome de las causas ingresadas en el sistema penal tal como se puede observar en la Figura $\mathrm{N}^{\circ} 2$.

31 En materia sustantiva en 2015 se modificó el Código Penal mediante una serie de normas, las Leyes Orgánicas 1/2015 y 2/2015, de 30 de marzo, y la Ley 4/2015 de Seguridad Ciudadana (denominada Ley Mordaza). En general estas normas: reubicaron dentro del código los delitos leves, crearon nuevos delitos leves, despenalizaron una serie de faltas de este modo ciertas infracciones pasaron al ámbito administrativo o incluso a la jurisdicción civil.

Sin perjuicio que las tendencias son bastante claras en las dos fuentes estadísticas más relevantes, existen algunas diferencias notables. Así, el Consejo General del Poder Judicial y la Fiscalía General del Estado, para el año 2018. Así, el CGPJ indica que ingresaron 3.151.698 y la Fiscalía por su parte informa que la cantidad es de 2.118.030, es decir, más de 1 millón de diferencia entre ambas fuentes. 
Asuntos ingresados en la Jurisdicción Penal

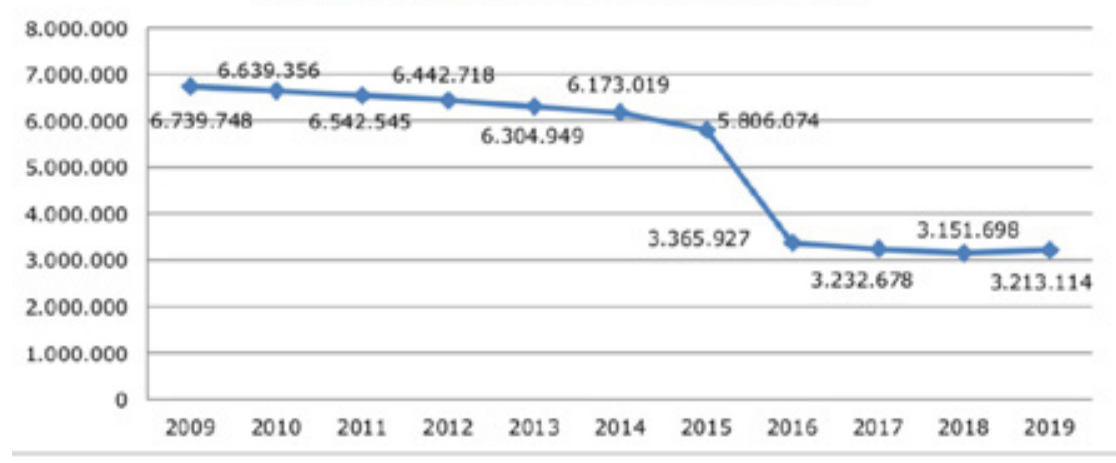

Figura 2. Asuntos ingresados en la jurisdicción penal.

Fuente: Informe Dato a Dato del Consejo General del Poder Judicial del 2019

La razón político-criminal de porqué se reformó la LECRIM el 2015 se debió en gran parte a la imposibilidad de aprobar un nuevo código procesal penal (Anteproyecto del 2013), el cual teóricamente iba a dar soluciones sistémicas a la justicia penal española. No obstante ello, las fuerzas políticas consensuaron el dictado de una especie de "ley de emergencia procesal", dando por resultado la Ley 41/2015, del 5 de octubre. Esta ley fue posible debido a que trataba cuestiones para las cuales no era necesario dictar una ley orgánica, estas materias fueron: a) la necesidad de establecer disposiciones eficaces de agilización de la justicia penal con el fin de evitar dilaciones indebidas, b) la previsión de un procedimiento de decomiso autónomo, c) la instauración general de la segunda instancia, d) la ampliación del recurso de casación y e) la reforma del recurso extraordinario de revisión (BOE, 2015, No 239) (33 $^{3}$.

33 Estos cambios legislativos fueron reforzados por la Circular 1/2015 de la Fiscalía General Estado, sobre pautas para el ejercicio de la acción penal en relación con los delitos leves tras la reforma penal promulgada. Este documento, tiene mucha relevancia pues da cuenta de un sinnúmero de elementos de contención al principio de oportunidad libre, otorgándonos una nutrida información acerca de cómo debiera operar el "Principio de Oportunidad Reglada". El ethos de la Circular se expresa así: "Se trata de una medida de complemento en el orden adjetivo de la reducción del número de tipos penales de 
La Fiscalía General del Estado, en su Memoria del 2019, indica que no hay duda que uno de los factores que propició la caída de ingresos al sistema justicia penal (entendiendo para estos efectos, solo la Fiscalía y Tribunales), ha sido la mejora en la "selección de casos". Esto se habría concretado con la instauración de un nuevo régimen de remisión de atestados $^{34} \sin$ autor ( $\sin$ autor conocido) por la policía a los juzgados y la despenalización de algunas conductas que hasta el 1 de julio de 2015 eran constitutivas de faltas (MFGE, 2019: 1070). De este modo, el art 284 LECRIM permite que la Policía, con carácter general (se excepcionan algunos ámbitos delictivos), no tenga que remitir, especialmente delitos contra la propiedad, al Juzgado ni al Ministerio Fiscal los atestados sin autor conocido (MFGE, 2019: 1072). Esto sin duda, descongestionó enormemente el sistema penal desde el año 2015 a la fecha, pues en los hechos casi todos los delitos patrimoniales sin "imputado o sospechoso conocido", no son elevados a la Fiscalía o Juzgados ${ }^{35}$.

Lo cierto es que cuantitativamente las conformidades como solución del sistema penal español ha tenido un aumento sostenido, incluso a pesar (o por lo mismo quizás) de los cambios legales, sustantivos y adjetivos, producidos con la gran reforma del año 2015, a los que haremos referencia párrafos más adelante ${ }^{36}$.

naturaleza leve efectuada en el CP con el fin de aligerar la carga burocrática que hasta la fecha representaba la tramitación y enjuiciamiento de las faltas".

34 Por atestado, deberemos entender el instrumento oficial (acta) en que una autoridad o sus delegados hacen constar como cierto algo. Normalmente se indican en un atestado la descripción del hecho denunciado, las diligencias instruidas, el o los posibles autores y la o las posibles víctimas del mismo (si las hubiere). La LECRIM se refiere al atestado en los artículos 292, 293 y 294.

35 Artículo 284 (LECRIM). "Inmediatamente que los funcionarios de la Policía judicial tuvieren conocimiento de un delito público o fueren requerido...No obstante, cuando no exista autor conocido del delito la Policía Judicial conservará el atestado a disposición del Ministerio Fiscal y de la autoridad judicial, sin enviárselo, salvo que concurra alguna de las siguientes circunstancias...”.

36 La Circular 1/2015 de la FGE, alude a la alineación entre el fallido anteproyecto de reforma de LECRIM (2011), que pretendía una nueva política criminal en el caso de los delitos de baja intensidad. "La reducción del número de faltas -delitos leves- en la nueva regulación que se introduce viene orientada por el principio de intervención mínima, y debe facilitar una disminución relevante del número de asuntos menores que, en gran parte, pueden encontrar respuesta a través del sistema de sanciones administrativas y civiles". 
Sin embargo, ese incremento ya se venía observando desde la reforma anterior (2002), que amplió las conformidades efectuadas en el procedimiento abreviado. Como se constata en la Figura $N^{\circ} 3$, las conformidades en el 2004 se ubicaban en torno al 40\% para una década después constituir casi el $60 \%$. Hoy ciertamente estas cifras son superiores.

\begin{tabular}{|l|c|c|c|c|c|c|c|c|c|}
\hline & $\mathbf{2 0 0 4}$ & $\mathbf{2 0 0 5}$ & $\mathbf{2 0 0 6}$ & $\mathbf{2 0 0 7}$ & $\mathbf{2 0 0 8}$ & $\mathbf{2 0 0 9}$ & $\mathbf{2 0 1 0}$ & $\mathbf{2 0 1 1}$ & $\mathbf{2 0 1 2}$ \\
\hline $\begin{array}{l}\text { Casos } \\
\text { Resueltos }\end{array}$ & 116.704 & 120.115 & 112.279 & 118.335 & 177.882 & 190.039 & 169.153 & 180.686 & 165.014 \\
\hline $\begin{array}{l}\text { Resuelto } \\
\text { elevado a } \\
\text { Juicio Rápido }\end{array}$ & 19,6 & 21,9 & 26,8 & 28,5 & 23,4 & 23,5 & 25,4 & 23,3 & 23,6 \\
\hline $\begin{array}{l}\text { Resuelto con } \\
\text { Conformidad }\end{array}$ & 40,2 & 40,0 & 41,7 & 46,2 & 55,8 & 57,2 & 55,5 & 55,7 & 58,0 \\
\hline
\end{tabular}

FiguRa 3. Forma de término de los procedimientos abreviados desde su reforma el año 2002/2003.

Fuente: Boletín de Información Estadística, No 32 marzo del 2013 a 10 años de los Juicios Rápidos (Ley 38/2002), Consejo General del Poder Judicial.

Lo cierto es que la caída de ingresos penales desde el 2015 y la consecuente disminución de las cargas de trabajo de hasta $56 \%$ entre el 2015-2016 (MFGE, 2019), no ha incidido en que disminuyan las conformidades. Tampoco ha tenido efectos en la mejora de la gestión de causas, ni ha afectado la calidad de las salidas al proceso penal ${ }^{37}$. De algún modo, en teoría se esperaría que este sistema "más liviano" no opte de modo mayoritario por la vía rápida (conformidades) en la solución de los conflictos penales. Sin embargo, si esto no ocurre, significa que hay otros factores, algunos extrajurídicos, que promueven la aceleración del proceso penal.

37 Otra modificación relevante que habría propiciado mayor aceleración al sistema es la modificación del Art. 324 de la LECRIM (2015), modificando el control temporal de los procedimientos penales, indicando seis meses prorrogables como plazo para terminar la investigación en asuntos de tramitación sencilla. 


\section{2) LA NATURALEZA DEL FRONDOSO SISTEMA DE CONFORMIDADES.}

No obstante, en ocasiones el asunto sobre el gerencial-eficientismo en el sistema penal pareciera un asunto abstracto, solo accesible al alto debate político-criminal y de la sociología del castigo, sí existe un contexto donde, tanto la literatura como los operadores del sistema (gestores político-criminales), están contestes en su materialización. Este ámbito no es otro que el ámbito de "los juicios rápidos y justicia negociada" $38 \mathrm{del}$ sistema de justicia criminal.

En la literatura estas herramientas procesales reciben diferentes denominaciones, a saber, "juicios fast track", "justicia penal negociada", "justicia consensual" 39 o "confesión en procedimiento" (ya sea reconociendo responsabilidad o admitiendo los hechos). Grosso modo, podemos entender a este tipo de términos judiciales como ciertos procedimientos $\mathrm{u}$ opciones procesales que la ley autoriza, cuando concurran ciertos requisitos, al objeto de que la tramitación de la acusación de un delito se realice de manera rápida, evitando un juicio oral, considerando así, que el sujeto acepta responsabilidad (acuerdo del acusado con los hechos, el delito y la pena) con una probable reducción de condena.

La doctrina internacional incluye en este grupo a procedimientos como el abreviado, las conformidades, el simplificado y otros relacionados con faltas (o de menor entidad) como son los denominados procedimientos monitorios. En España estas herramientas son antiguas ${ }^{40}$ y la literatura usualmente pone de relieve su débil sistematización y su naturaleza compleja (Gómez Colomer, 2012:23), algunos incluso

38 Desde un punto de vista crítico, cuando analizamos este modelo de juzgamiento, en realidad nos encontramos frente a meros procedimientos rápidos, pues ni siquiera se presentan los elementos básicos del juzgamiento para hablar de "juicios rápidos".

39 Esto se basa en el denominado "principio del consenso procesal".

40 En el modelo español el sistema de conformidades data desde el año 1835 e incluso desde antes para los delitos flagrantes (Fraga, 2018:13; Gimeno Sendra, 2002). Reforzándose estos procedimientos con la reforma de fines del siglo XIX, más el dictado de la actual LECRIM, y su apertura definitiva en las reformas de 1988. Ciertamente sólo a partir de esta última reforma se puede hablar de un auténtico modelo de conformidades acoplado a una visión "aceleracionista" de la justicia penal. . 
hablan de un verdadero "caos procedimental" (Ferré, 2018; Del Moral García, 2015; Barona Vilar, 1994). Sin embargo, también se destacan elementos positivos del sistema de conformidades, como su diversidad y amplia variedad de opciones procesales que ofrece, esto ha llevado a algunos autores a hablar de la "frondosa selva de conformidades" ${ }^{41}$ (Gimeno Sendra, 2004).

Lo cierto es que la conformidad no es un procedimiento, ni un juicio en sí mismo, sino que constituye un modo alternativo de resolver el conflicto penal (convenio, acuerdo, declaración de culpabilidad), en otras palabras, "es un tipo de término al proceso penal", "una opción procesal que la ley otorga" (Fraga, 2018: 27), o un "allanamiento penal" como decía Niceto Alcalá-Zamora $(1962)^{42}$. Sin embargo, es innegable que desde una perspectiva estadística (vista en párrafos previos), más que un modo alternativo, es el núcleo para resolver el litigio penal ${ }^{43}$. Por esta razón, la conformidad es algo amplio, mucho más que una simple confesión (De Diego Díez, 1997), encontrándola dispersa en distintos procedimientos como el abreviado, ordinario o procedimientos rápidos (Del Moral García, 2008:11; Fraga, 2018). Sin embargo, es en estos últimos "enjuiciamientos", donde toma realmente un cariz "aceleracionista” (Hernández, 2002), debido probablemente, a que las ansias por el eficientismo, son mayores en éste, que en otros procedimientos. Por tanto, la conformidad no es un procedimiento, según la LECRIM es una forma de poner fin al procedimiento, por tanto sería parte del procedimiento.

41 Esta "frondosidad" puede interpretarse como otra expresión más de la aplicación del principio de oportunidad reglada. Alejándose así del modelo ilimitado del principio de oportunidad del modelo norteamericano (Ferré, 2018).

42 Es posible observar la diferente nomenclatura utilizada para tratar la misma materia, denominándosele a las conformidades como "institución", "modelo", "procedimiento", "tipos”, "modalidades”, “juicio”, “sistema”, etc. (Hernández, 2002; Del Moral, 2008; Gómez-Colomer, 2012; Ferré, 2018; Fraga, 2018).

43 Este fenómeno pareciera ser de carácter global. Así en Alemania ya se habla de justicia criminal sin juicios (Weingend, 2021). En Estados Unidos por ejemplo, los juicios orales o de jurados son marginales, existiendo una verdadera tasa de administrativización del sistema penal (Langer, 2019). Por ello, cuando se habla del sistema estadounidense de justicia se dice que es un "sistema penal de conformidades", no un sistema de juicios (Ferré, 2018:3). 
En términos sintéticos el "frondoso" sistema (Gimeno, 2004) de conformidades español se compone del siguiente modo ${ }^{44}$ : I) Conformidades dentro de la LECRIM, y estas a su vez se podrían clasificar como: a) Conformidades del procedimiento ordinario, arts. 655 y 688 y ss. LECRIM. Estas son posibles en el escrito de calificación y al inicio del juicio oral. b) El Procedimiento Abreviado de la regla $5^{\mathrm{a}}$ del $\mathrm{n}^{\circ} 1$ del art. 779 , el $3^{\circ}$ del art. 784 y el $n^{\circ} 1$ del art. 787 LECRIM. Esta es posible en cualquier momento previo al auto de continuación de diligencias por los trámites del procedimiento abreviado hasta el acto de juicio y antes de practicarse la prueba. c) En el procedimiento para el enjuiciamiento rápido de determinados delitos. Esta es posible ante el Juzgado de Guardia una vez tomado conocimiento del contenido de la acusación ("conformidad" del art. 801 LECRIM). También sería posible en cualquier momento antes de iniciarse la prueba en el juicio oral. d) El proceso por aceptación de Decreto.

Además, existen otras conformidades que podemos denominar II) Conformidades fuera de la LECRIM, que serían: a) La conformidad ante el Tribunal del Jurado. Esta sería posible en el juicio oral produciendo la disolución del jurado. b) La conformidad del procedimiento de menores, siendo posible llevarla a cabo en diversidad de instancias desde la audiencia con las alegaciones que contiene el escrito del Ministerio Fiscal. c) La conformidad dentro de la Jurisdicción militar, la cual sería factible tras la apertura del juicio oral hasta el comienzo de las sesiones del juicio mismo. Ciertamente, no es el espacio para enfocarnos en cada uno de los tipos de conformidades (o procedimientos donde son admisibles), pero sí nos referiremos a aquellas que tienen un marcado sello gerencial-eficientista ${ }^{45}$.

44 Las conformidades no tienen una definición legal. En todo caso en la expresión de motivos de la Propuesta del Código Procesal Penal del 2013, se indicaba que las Conformidades es, aquella institución que permite la emisión de sentencia condenatoria sin juicio, por la aceptación de la pena más grave solicitada, que el código potencia mediante la extensión de su ámbito.

45 También es reseñable la existencia de una Conformidad de las Personas Jurídicas, incorporada con la Ley 37/2011, que modificó el art. 787, y que indica "cuando el acusado sea una persona jurídica, la conformidad deberá prestarla su representante especialmente designado...dicha conformidad...podrá realizarse con independencia de la posición que adopten los demás acusados, y su contenido no vinculará en el juicio que se celebre con relación a estos”. 
Sin duda, el hito moderno en la configuración de las conformidades es la introducción del procedimiento abreviado en 1989 (Ley Orgánica 7/1988, 28 de diciembre). Este cambio legislativo, abrió las puertas a la doctrina del "Consenso Procesal", y aunque no introdujo grandes cambios (Gómez Colomer, 2012), sí amplió la tipología (para delitos de menos de 9 años de prisión) y mejoró los momentos procesales para las conformidades, y estimuló a la Fiscalía General del Estado para fomentar la utilización de esos "métodos paccionados" 46 (en el modelo anterior la conformidad consistía en que el imputado solo se adhería al escrito de acusación). Lo cierto es que esa nueva filosofía o "apología eficientista" quedaría reflejada de modo claro en la Circular 1/1989 de la Fiscalía General del Estado (Del Moral, 2008).

El siguiente hito fueron las Leyes 8/2002 y 38/2002 que modificaron la LECRIM, introduciendo los procedimientos rápidos e inmediatos para determinados delitos y faltas ${ }^{47}$. Probablemente es una de las manifestaciones más explícitas de esta visión gerencial/eficientista, también se le denomina "conformidad premiada". Esta conformidad tiene como elemento más sobresaliente la reducción en un tercio de la pena solicitada en la acusación (evitando el juicio oral y en ocasiones la instrucción). Sus raíces distinguiblemente gerenciales se observan en la expresión de motivos de la Ley 38/2002, pues establece como objetivos: “...la agilización de los procedimientos, la mejora de los procedimientos abreviados, el enjuiciamiento inmediato de los delitos menos graves y flagrantes y la simplificación de trámites en las grandes causas. Indudablemente, el sistema de conformidad que implementa (tramitada en el propio Juzgado de Guardia y con la automática reducción de la pena en el tercio) debe contribuir decisivamente a la agilización...”.

46 Ver en la Circular 1/89 Fiscalía General del Estado. https://www.fiscal.es/ memorias/estudio2016/PDF/CIR/CIR_01_1989.pdf.

47 Para potenciar estos cambios en la Circular 1/2003, de 7 de abril de la Fiscalía General del Estado, sobre procedimiento para el enjuiciamiento rápido e inmediato de determinados delitos y faltas y de modificación del procedimiento abreviado, deja en claro su indiscutible tenor gerencial del siguiente modo “...que los daños ocasionados por el delito, obligan a los poderes públicos a empeñar todos sus esfuerzos con el fin de hacer realidad la aspiración generalizada de mayor celeridad y eficacia". 
En términos más contemporáneos un ejemplo del sello gerencialeficientista es "la conformidad por decreto". Esta emerge cuando el año 2013 se hace imposible la aprobación de un nuevo código procesal penal para España, lo cual se compensó político-criminalmente con la promulgación el año 2015 con una legislación denominada de "Ley de Fortalecimiento del Enjuiciamiento Criminal para la agilización de la Justicia Penal y el Fortalecimiento de las garantías procesales". De este modo, se introduce una especie de Procedimiento Monitorio Penal, para la resolución rapidísima para delitos de menor gravedad y faltas con el objetivo de aligerar la carga de trabajo de los tribunales. La instauración de este procedimiento tenía como objetivo otorgar rapidez y economía en la respuesta punitiva a estas infracciones, se buscaba en definitiva la máxima eficacia en la resolución del conflicto (Fraga, 2018; Ferré, 2018; Colomer, 2012; Castillejo, 2015). Se constituye de este modo una conformidad en la fase de instrucción penal. De forma crítica, Muerza Esparza (2015) dice que se instaura un nuevo instrumento jurisdiccional para imponer penas leves o menos graves de la manera más rápida posible en el que no existen propiamente fases del proceso y que desnaturaliza absolutamente el significado del proceso penal ${ }^{48}$.

\section{3) Argumentos a favor y en Contra del modelo de JUICIOS O PROCEDIMIENTOS RÁPIDOS.}

Los fundamentos para la existencia de las conformidades y de otros procedimientos de este tipo, basculan entre razones de carácter técnicoutilitaristas, como la economía y la celeridad procesal, y argumentos valórico-jurídicos como la idea de "pronta justicia". Ahora bien, desde una perspectiva político-criminal mucho más general, se suelen indicar justificaciones que se mueven bajo la idea de que las conformidades cooperan a la reinserción social del sujeto, aligeran la carga de trabajo

48 El Anteproyecto de LECRIM 2020 (ART. 164 a 173) mantiene en general las regulaciones de las Conformidades, así, no se modifica la negociación extrajudicial de las partes, se amplía la posibilidad a cualquier procedimiento, delito y pena, sin las restricciones actuales (salvo el jurado que mantiene su régimen actual), además se puede rebajar la pena hasta en un grado (la mitad de la pena), es decir, mayor que el tercio actual. 
de las agencias penales, o bien, simplemente indican que el sistema penal debiera quitarse ese cúmulo "graso" de casos menores, facilitando la descongestión judicial (Ferré, 2018) ${ }^{49}$. De este modo, se permitiría que el sistema penal dirija sus esfuerzos sobre la delincuencia difícil, como la económico-corporativa, la corrupción o la de poderosos ${ }^{50}$. Incluso a nivel de justicia internacional se destaca la ventaja del plea barganining, para mejorar la eficiencia en la aclaración de delitos que de por sí son complejos de investigar (Turner, 2017:240-241). Lo cierto, es que no son pocos los autores que asumen la realidad de la justicia negociada, pero promueven que esta sea "fuertemente reglada", logrando de este modo balancear sus ventajas y desventajas político-criminales (Gómez-Colomer, 2012).

Por su parte, quienes critican el uso masivo de estos instrumentos, argumentan que estamos ante una verdadera renuncia, crisis y degradación de la jurisdicción penal (Schünemann, 2012), dado que no se tutelan derechos de los acusados, ni se protege a la sociedad (Del Moral, 2008:6), diluyéndose así la confianza en el sistema judicial (Viano, 2012), hasta el punto que, en ocasiones, inocentes pueden aceptar la condena a fin de no recibir un castigo mayor, lo que acrecentaría indirectamente el porcentaje de la estadística del error judicial (Lascaurín y Gascón, 2018). Indican así, que la valoración de la responsabilidad penal y la cuantificación penológica, estaría entregada a la simple negociación de los intervinientes del sistema. Otros, argumentan que el objetivo de la descongestión del sistema de justicia penal, ha impulsado la creación de sistemas rápidos de "gestión de la flagrancia", llevándonos a una verdadera "macdonalización" del sistema penal (Gañon, 2007). En general las críticas convergen en

49 Estadísticamente se entiende por tasa de resolución el cociente entre los asuntos resueltos y los ingresos en un determinado período, poniendo en relación el volumen de ingresos con la capacidad resolutiva. Tasa de descongestión: cociente donde el numerador está formado por suma de los asuntos pendientes al inicio del período y donde el denominador son los asuntos resueltos en dicho período. (La Justicia Dato a Dato, 2019:41, www.poderjudicial.es.).

50 En diferentes procesos reformadores no es inusual que se esgriman razones de carácter económico, por ejemplo en la reforma al sistema de justicia penal en Chile, el Informe Valdivieso, hizo una serie de estimaciones basadas en la racionalidad económica, y se calcularon los gastos tanto en los procedimientos abreviados como en las salidas alternativas al procedimiento (González, 2018:228). 
que el modelo "fast track de justicia penal", ha contribuido de manera significativa y acelerada a la procesualización ${ }^{51}$ de la justicia, cuyo costo más alto es la encarcelación masiva, así como una retirada de las discusiones sustantivas al interior de los juicios penales con consecuencias garantistas negativas palpables.

Otra crítica usual, es que los procedimientos de negociación, son abiertamente desequilibrados, en muchos casos en un contexto de "coacción o presión indirecta”, o bien, configurados mediante "engañosas ofertas" o "tentadores incentivos" de rebajas de condena hechas a los imputados (Ferré, 2018). De este modo, primarían las negociaciones clandestinas (para-procesales), ausentes de control judicial (Schünemann, 2012; Del Moral, 2008: 5). En síntesis, el acuerdo se parecería más a un "contrato de adhesión" o a lo sumo un "regateo", ${ }^{52}$ más que a una negociación libre y espontánea ${ }^{53}$. De este modo, aumentan las probabilidades de que se aceptan acusaciones, referidas a hechos respecto de los cuales no se es realmente responsable, lo cual tendría un efecto evidente sobre la eventual condena de inocentes (Viano, 2002; Del Moral, 2008; Ferré, 2018).

Estas críticas son observables en la práctica procesal penal española. Así, en un elevado número de casos, los escritos de calificación provisional del Ministerio Fiscal (Fiscalía) difieren en caso de que se llegue a una conformidad o no. En el primer supuesto (con conformidad), se solicita una pena inferior, en el segundo (sin conformidad), se agrava la pena solicitada. Desde la óptica de la fiscalía esto aparenta normalidad y no se entiende como chantaje, sino como un doble beneficio. Comprenden

51 "Procesualismo", entendido como aquella perspectiva que identifica la realidad social, en este caso la realidad político-criminal del sistema de justicia, como constante flujo y cambio, como un proceso puro en sí mismo, por tanto “estandarizable" en todos sus elementos. Alejándose así de un concepto más sustancial de la realidad, por extensión lejano a un concepto sustancial de la política criminal y de la justicia penal.

52 De hecho una de las acepciones de la "bargaining" (plea bargaining), se asimila a regateo, es decir, la práctica habitual realizada en los bazares por los mercaderes para fijar un precio (en este caso una pena).

53 Un factor que impulsaría a los Fiscales y defensores, en diversas realidades político-criminales se refiere a las presiones de cumplimiento estadístico a las cuales son sometidos. Obviamente esto es más intenso en aquellos sistemas donde la gerencialización alcanza cotas muy altas, especialmente en los modelos angloamericanos y latinoamericanos. 
que el primer beneficio (si se produce conformidad) se daría por la recalificación considerando los hechos como menos graves, por tanto se pide una pena inferior, el segundo beneficio (en los supuestos de los procedimientos seguidos ante el juzgado de guardia especialmente), se produciría por la reducción del tercio de la condena. Sin embargo, desde el punto de vista de la defensa, este doble beneficio es una ilusión pues el tercio lo establece la propia ley, así realmente estaríamos ante un verdadero chantaje para llegar a la conformidad, al presentarse al defendido dos opciones de futuro, una cierta con menor gravedad, y una incierta y agravada a pesar de tratarse de los mismos hechos.

Otras críticas, son que alteran la competencia de los poderes públicos, pues las fiscalías realizan "ofertones" penológicos, que diluyen lo determinado por el legislador ${ }^{54}$. Además, estas rebajas pueden basarse en elementos inmorales, como sería el uso de falsos testimonios o con excesivas delaciones compensadas (Ferré, 2018). Paradójicamente quienes critican el "garantismo" como una política-criminal excesivamente condescendiente con la delincuencia, también critican esta institución, pues para ellos, la justicia negociada establece finalmente penas menores a lo que correspondería, fomentando la "impunidad penal" 55 . Otro cúmulo de cuestionamientos, pero ligados a temas procesales, son la existencia de una asimetría de información entre Fiscalía y defensa, la penalización indirecta del "no acuerdo" (persecución vengativa), la aceptación de acuerdos por la imposibilidad económica de sostener un juicio, o el rol indirecto de la Policía mediante la provisión de pruebas falsas o al menos no contrastadas en un juicio.

54 Sin duda, este es un punto crítico del modelo de justicia negociada. Pues si el Estado asume con tanta facilidad la reducción de penas (en el caso español un tercio), significaría que las penas en los códigos penales ¿están “infladas”?, tanta diferencia no puede consistir únicamente en una retribución por llegar a un acuerdo, no olvidemos que se trata ni más ni menos que de un tercio de reducción de la pena. Por ello, habría que reflexionar sobre qué parte de la reducción responde realmente al incentivo del acuerdo (razón político-criminal) y qué parte, amortiza indirectamente, un artificial incremento penológico, establecido ab initio en el Código penal (razón penal).

55 Ferré (2018), indica que en el sistema estadounidense criticas similares se hacen desde la vereda de grupos conservadores que defienden la idea de Ley y Orden. 
Críticas hechas desde una visión organizacional, se refiere al uso falaz y equivocado de los conceptos “eficiencia y resultados” en el sistema penal, dando por hecho que el modelo de los juicios rápidos son la panacea para los problemas del sistema de justicia criminal, cosa no demostrada ciertamente. Creemos que ante la tensión entre eficiencia y justicia, debe primar esta última, por ello, algunos autores como FixFierro (2006) hablan de la "juridificación" de la eficiencia. En cualquier caso, las críticas de este estilo de justicia penal, ya era criticada por autores clásicos de la doctrina penal, así Juan Bustos (2007) indicaba que “...bajo la excusa de la búsqueda de eficacia y el exceso de carga de los tribunales se han introducido procedimientos que al final han significado pérdida de garantías para los inculpados...estos procedimientos chocan abiertamente contra principios garantistas básicos, como la oralidad y la publicidad del proceso ... se vulneraría el principio de igualdad, pues aquel sujeto que se niega a cooperar se vería expuesto a un trato más duro" (Bustos, 2007: 346).

Lo cierto es que los procedimientos rápidos existían antes de la emergencia del paradigma gerencial ${ }^{56}$. Lo que sucede es que hay un cambio en la intensidad de su uso, probablemente presionado por la necesidad de gestionar un contexto de "masificación judicial" pocas veces visto en la historia judicial. Además, se instaló la idea de que estos procedimientos permiten responder de mejor modo a la demanda ciudadana, debido a la mayor celeridad en la resolución de los asuntos penales (Silva Sánchez, 2006). Así, el asunto ya no sería solo la introducción de técnicas procesales específicas para descongestionar el sistema penal, sino que se dan en un momento en que las técnicas gerenciales son bienvenidas. Esta bienvenida se daría por dos razones: primero, porque no se ha propuesto un modo alternativo para gestionar la masificación de casos, y segundo, porque el modo gerencial de entender la justicia criminal, serviría para responder a la exigencia de que el proceso penal se haga cargo también de la eficacia,

${ }^{56}$ Lo cierto es que en España desde 1835 ya se conocen este tipo de procedimientos. Algo similar ocurre en otros contextos como el alemán o la larga tradición del plea bargaining en Estados Unidos. Sin embargo, no será hasta la gran reforma de la Ordenanza Procesal Penal alemana de 1974 cuando se introduce el principio de oportunidad reglado y el monopolio de la acción penal pasa al Ministerio Público (Fraga, 2018:37-57). 
la persecución penal, la seguridad pública, en definitiva, convertir al proceso penal en otra herramienta de lucha contra la delincuencia (Gascón, 2009: $15-16)^{57}$.

Por tanto, si concebimos que el discurso gerencial/eficientista se acopla de buena manera en el ámbito procesal penal español, de algún modo moderaría la hipótesis que indicamos en la introducción del artículo, en el sentido que los fenómenos "gerenciales" interaccionan más "amigablemente" en los sistemas acusatorios (adversariales), que en los inquisitoriales o acusatorios "espurios" ${ }_{58}$. Así, el gerencial/eficientismo, operaría de modo independiente al modelo procesal imperante, quizás de un modo menos intenso que en el acusatorio, por la propia resistencia del principio de legalidad versus oportunidad, y a las resistencias culturales de cada sociedad (oportunidad reglada). Pero al fin y al cabo los objetivos "eficientistas" están anclados en factores no solo internos (masificación de casos, atraso judicial, etc.), sino que también externos (uso de la informática, estadística, demanda social de celeridad, etc.). Lo anterior explicaría que, si bien en las reformas latinoamericanas el fenómeno gerencial parece más evidente que en Europa, esto se debería en gran parte a que los sistemas de justicia europeos, históricamente han tenido unas burocracias judiciales más consolidadas, lo cual, actuaría como dique de contención a la colonización de un gerencialismo intenso. Esto probablemente no ha operado en otros ámbitos europeos donde la construcción organizacional es más reciente, específicamente lo que se relaciona con la gerencialización de la "burocracia paneuropea", ya sea a través de la Comisión Europea o incluso de las propias cortes europeas.

A día de hoy el sistema de conformidades, tal como lo hemos exhibido previamente, es la salida mayoritaria al sistema penal. Así los procedimientos que, en teoría son el núcleo de cualquier modelo de

57 Otra transformación en los sistemas de justicia criminal contemporáneos (además de las obligaciones securitarias), es convertir el proceso penal en instrumento reparador de la víctima, no sólo en términos materiales sino también simbólicos. Esto ciertamente es coherente con el denominado fenómeno político criminal del "redescubrimiento de la víctima en el sistema penal” (Gascón, 2009:12).

58 En el modelo de justicia penal francés también se ha rastreado el impacto de las lógicas gerenciales, dando cuenta de ello bastante literatura (Vigour, 2006; Mouhanna y Vesentini, 2016). 
enjuiciamiento, es decir, juicio oral propiamente tal y juicios por jurado, tienen un papel más bien de carácter simbólico que uno protagónico. Por ello, algunos autores, proponen una visión realista y conciliadora, proponiendo la regulación de la conformidad más que su eliminación (Gómez-Colomer, 2012; Ferré, 2018). Pero esto no debe ocultar que detrás, de la "americanización" del sistema de justicia penal español, persisten los problemas comunes a muchos sistemas penales occidentales. Estos son, la masificación de casos y los atrasos o cargas judiciales. Así, ante la proliferación de conflictos, los sistemas de justicia penal han recurrido al uso intensivo de la gestión para controlar en mínimos razonables esta situación y el marco teórico seleccionado (directa o indirectamente) es lo que se suele denominar el New Public Management.

\section{Conclusiones}

a) A pesar de los escasos estudios realizados, tanto sobre el gerencialismo y como sobre el eficientismo en España, la penetración de sus lógicas en el sistema penal es indudable. ${ }^{59}$ Ciertamente, esta ha ocurrido de manera diferente a otros contextos, como por ejemplo respecto del modelo angloamericano (especialmente estadounidense) donde el ethos pragmático es casi la esencia del modelo de justicia. O bien, respecto de las reformas procesales penales latinoamericanas, que se movieron desde un sistema de rasgos inquisitivos a uno de corte acusatorio. Estas últimas, entre otras razones, tuvieron su justificación en el abandono de los modelos de justicia propios de épocas dictatoriales, como también se insertaron en procesos de modernización general de diversos estados latinoamericanos (Sozzo, 2020; Binder, 2000; González, 2015; Duce, 2009; Langer, 2007). Por tanto, se vuelve interesante que a pesar de que el modelo que rige en España no es "acusatorio puro", bastantes de las lógicas eficientistas y

59 Es curioso, que la literatura hasta ahora no desarrollado una ligazón entre el sistema de conformidades o juicios rápidos con el debate que se da en diferentes contextos internacionales sobre gerencialismo y eficiencia penal. Una de las razones para explicar esta situación es la situación "peculiar" de los estudios de derecho procesal penal en el contexto español, su relativo aislamiento respecto del campo de los estudios penales y más aún de los estudios criminológicos. 
gerenciales que la literatura internacional ha detectado en otros sistemas, se encuentran presentes en el sistema penal español, a saber: aceleración de ciertos procedimientos (juicios rápidos, conformidades o flagrancias) y apertura a procedimientos monitorios penales (aunque no necesariamente reconocidos con ese nombre), incorporación de indicadores y metas de gestión en las agencias penales (especialmente policiales aunque con un éxito discutible), planificación estratégica (especialmente a nivel central), protocolización y estandarización de procedimientos, incorporación de normas ISO (especialmente en ámbito policial), privatización de servicios específicos (justicia juvenil, ejecución de penas no privativas de libertad y servicios de reinserción de ex reclusos), utilización de tabulación de riesgos (especialmente en el campo penitenciario, y en los procedimientos de intervención en violencia de género), uso intenso de las TICs, entre otras características.

b) Lo anterior nos hace pensar que hay otros fenómenos jurídicos, tecnológicos y socio-económicos, que están más allá del diseño procesal, y que a su modo están consolidando un "modelo aceleracionista y eficientista en los sistemas procesales penales". En esta línea se puede asumir que el sistema de justicia penal opta por un modelo aceleracionista para las causas "mas licuables" (flagrancias, por ejemplo), aquellas de fácil tramitación y escaso inconveniente garantista, y al mismo tiempo, opta por una justicia penal más ralentizada (con menos garantías), para aquellos delitos más graves, difíciles de investigar y de procesar (como el crimen organizado por ejemplo). Ciertamente esto es discutible pues puede convivir una modelo aceleracionista con notables pérdidas de garantías. A esta pérdida de garantías procesales algunos le han denominado un "proceso penal del enemigo" (Gascón, 2009).

Sin embargo, es bueno advertir, que lo que pudiera parecer razonable en términos de modular la intensidad de gestión del sistema, acarrea una trampa, pues finalmente la disminución de garantías para combatir la "alta criminalidad", termina trasladándose y normalizando en los delitos de "menos intensidad" ${ }^{60}$. Sin embargo, se requiere de

60 Una crítica similar ya se hizo en su tiempo respecto del derecho penal de dos velocidades. Al fin y al cabo la pérdida de garantías se manifiesta más intensa en la delincuencia clásica, es decir, en aquellos cometidos por las clases 
más investigaciones para afinar las intersecciones de estos diferentes fenómenos, para ello es imprescindible observar el sistema de justicia penal, no sólo desde una óptica procesal penal como concatenación de plazos y procedimientos, sino que complementariamente se necesita hacerlo desde el cruce disciplinar entre el derecho, la sociología del castigo, la política-criminal y las ciencias sociales en general.

b) Una de las manifestaciones palpables de este paradigma eficientista, se consolida en el modelo o institución de las conformidades, materializado especialmente en los procedimientos rápidos o abreviados, y en general, en todo procedimiento donde es posible llevar adelante la justicia negociada. Las estadísticas son contundentes, la conformidad corresponde casi al 70\% del modo en que termina un litigio penal ordinario y en el $90 \%$ de los juicios rápidos es la manera preferente (obviamente lo normal será que sean sentencias condenatorias). Así, se replica lo que sucede en otros contextos de occidente, donde "el juicio" propiamente dicho (y el de los Jurados) realmente tienen un rol testimonial. Esta administrativización de enormes sectores del sistema de justicia penal, sería además un fenómeno coherente con la denominada "administrativización del Derecho penal”. Por el momento no existen razones para pensar que esta deriva pueda revertirse, y lo esperable es que las cifras se estabilicen por sobre el $90 \%$ en este tipo de soluciones. Una forma de morigerar los "efectos perversos" que esto puede generar sería un mayor control judicial sobre este tipo de acuerdos (una conformidad reglada), con el evidente riesgo de conculcar la celeridad vía aumento de la burocratización ${ }^{61}$. Otro paliativo sería ensanchar el camino a la "justicia restaurativa” para poder tener una justicia negociada (conformidades) con mayor contenido (Gaddi, 2020). Soluciones similares han sido propuestas en España por el Grupo de Estudios de la Política Criminal (GEPC, 2014).

socialmente más desintegradas, más que en la delincuencia socioeconómica o de poderosos (Díez-Ripollés, 2004).

${ }^{61}$ Otro problema que puede suscitarse por el exceso de control, es la contaminación del juzgador (en los casos en que la conformidad no se produzca en los juzgados de instrucción o de control), al conocer los hechos con anterioridad a ser juzgados y conocer los detalles de la negociación entre Fiscalía y defensa. 
c) Un argumento para aquellos que propugnan la creación de un cuerpo gerencial en la justicia penal española, sería que realmente nunca se ha logrado transformar sistémicamente la dimensión organizacional del sistema criminal. Es más, el intento más amplio al respecto fue la creación de la Nueva Oficina Judicial, la que realmente no terminó de implementarse por diversas razones (políticas, administrativas, de cultura organizacional). Además, estos cambios apuntaron más bien a transformar los despachos judiciales, que a un cambio organizacional real en las agencias penales. A lo anterior hay que agregar que es difícil pensar una mutación organizacional de esa escala si previamente no se hacen las transformaciones necesarias en el plano adjetivo (un nuevo código procesal penal) que reemplace la antigua LECRIM. Lo anterior es relevante, pues, a pesar de que organización y mundo jurídico corren en muchas ocasiones por carriles separados, son innegables las relaciones que existen entre unas y otras, por ello es recomendable que al mismo tiempo que se transforme la ley adjetiva procesal penal, se evalúe la organización que la pondrá en ejecución.

\section{BIBLIOGRAFÍA}

ALCALÁ-ZAMORA y CASTILLO, Niceto, (1962). El allanamiento en el Proceso Penal. Buenos Aires: EJEA.

ALONSO CUEVILLAS, Jaume, (2015). Eficiencia y transparencia del sistema de justicia español en el contexto europeo: Análisis comparativo y propuestas de mejora. España: Editorial: J.M. BOSCH.

ARMENTA DEU, Teresa. (2015). Debido proceso, sistemas y reforma del proceso penal. Revista Brasileira de Direito Processual Penal, Porto Alegre, vol. 1, n. 1, p. 121-139. http://dx.doi.org/10.22197/rbdpp.v1i1.7

BARONA VILAR, Silvia, (1994). La Conformidad en el Proceso Penal Español. Valencia: Tirant Lo Blanch.

BINDER, Alberto, (2000). Ideas y materiales para la reforma de la justicia penal, Buenos Aires: Ad-Hoc.

BRANDARIZ GARCÍA, José, (2016). El modelo gerencial-actuarial de penalidad. Eficiencia, riesgo y sistema penal, Madrid: Editorial Dykinson. 
BUSTOS, Juan. (2007). Obras completas. Derecho penal. Parte General, Santiago de Chile: Editorial Jurídica.

CARVAJAL, Zunilda, (2010). Las reformas procesales penales en Francia. Revista de Derecho y Ciencias Penales, № 15 (23-33), 2010, Universidad San Sebastián (Chile) CASTILLEJO MANZANARES. Raquel, (2015). Últimas reformas procesales. El proceso por aceptación de decreto. Diario La Ley No 8544.

DE DIEGO DÍEZ, Luis Alfredo. (1997). La conformidad del acusado, Tirant lo Blanch, Valencia, 1997.

DEL MORAL GARCÍA, Antonio. (2008). La conformidad en el proceso penal. Reflexiones al hilo de su regulación en el procedimiento español. Revista Auctoritas Prudentium. Guatemala.

DEL MORAL GARCÍA, Antonio. (2015). Otra vez sobre la conformidad y conformidades en el proceso penal. En DEL MORAL GARCÍA, Antonio.; VERDEJO, Jaime. Fernando Herrero Tejedor Algar - Liber Amicorum. Pp, 481-508. Madrid: Editorial Colex.

DEL ROSAL BLASCO, Bernardo, (2009a). ¿Hacia el Derecho penal de la postmodernidad? Revista Electrónica de Ciencia Penal y Criminología (RECPC).

DEL ROSAL BLASCO, Bernardo. (2009b). La estrategia actuarial de control del riesgo en la política criminal y en el Derecho. En CARBONELL MATEU, Juan Carlos et al. (coords.), Constitución, derechos fundamentales y sistema penal: (semblanzas y estudios con motivo del setenta aniversario del profesor Tomás Salvador Vives Antón. Vol. 1, Valencia: Tirant lo Blanch.

DÍEZ-RIPOLLÉS, José Luis, (2004). El nuevo modelo de seguridad ciudadana. Revista de Derecho penal y Criminología.

DÍEZ-RIPOLLÉS, José Luis, (2012). Un diagnóstico y algunos remedios de la política criminal española. Revista de Estudios Judiciales. No 16. Pp: 31-54. doi:10.5354/0718-4735.2013.29492

DOMÍNGUEZ, José Luis.; RODRÍGUEZ, Anabel, (2003). Lógica actuarial, seguridad y sistema de justicia criminal. En DA AGRA, Cándido et al. (eds.). La seguridad en la sociedad del riesgo: Un debate abierto. Barcelona: Atelier.

DUCE, Mauricio, (2009). Reformas a la justicia criminal en América Latina: una visión panorámica y comparada acerca de su gestación, contenidos, resultados y desafíos. En DAMMERT, Lucía (ed.). Crimen e inseguridad, políticas, temas y problemas en las Américas. Santiago de Chile: FLACSO Chile-Catalonia, Pp: 189-224.

FARALDO, Patricia, (2008). Estrategias actuariales en el control penal de la violencia de género. En MUÑOZ CONDE, Francisco. Problemas actuales del Derecho 
penal y de la Criminología. Estudios penales en memoria de la Profesora Dra. María del Mar Díaz Pita. Valencia: Tirant lo Blanch, págs. 737 y ss.

FEELEY, Malcolm.; SIMON, Jonathan. (1992). The New Penology: Notes on the Emerging Strategy of Corrections and its Implications. Criminology, vol. 30, núm. 4, 1992, págs. 449 y ss. https://doi.org/10.1111/j.1745-9125.1992.tb01112.x

FEELEY, Malcolm; SIMON, Jonnathan, (1994). Actuarial Justice: the Emerging New Criminal Law. En NELKEN, David. The Futures of Criminology. Londres: SAGE Publications. págs. 173 y ss.

FEELEY, Malcolm, ; SIMON, Jonathan, (2003). The Forms and Limits of the New Penology. En BLOMBERG, T. G.; COHEN, S. Punishment and Social Control. New York: Routledge, págs. 75 y ss.

FERNÁNDEZ, Cristina; BRANDARIZ, José, (2016). Transformaciones de la penalidad migratoria en el contexto de la crisis económica: El giro gerencial del dispositivo de deportación. InDret, no 4, pp. 1-25.

FERRÉ, Juan Carlos, (2018). El Plea Bargaining, o cómo pervertir la justicia penal a través de un sistema de conformidades low cost. Revista Electrónica de Ciencia Penal y Criminología, $\mathrm{N}^{\circ} 6$.

FIX-FIERRO, Héctor, (2006). Tribunales, justicia y eficiencia. Estudio sociojurídico sobre la racionalidad económica en la función judicial. México, D.F.: Universidad Nacional Autó- noma de México. 332 pp. ISBN 970-32-2798-8.

FRAGA MANDIÁN, Javier, (2018). Las diversas manifestaciones del la conformidad en el Derecho procesal español. Madrid: Editorial SEPIN.

FREIBERG, Arie, (2005). Managerialism in Australian criminal justice: RIP for KPls. Monash University Law Review. V. 31. No 1, Pp: 12-36.

GADDI, Daniela, (2020). Materiales para una conformidad restaurativa. Estudios Penales y Criminológicos, 40. https://doi.org/10.15304/epc.40.6928

GAÑON, Gabriel, (2008). ¿La macdonalización del sistema de justicia criminal?: La aceptación improvisada de los paquetes de reforma judicial para el tercer milenio. En BERGALLI, Roberto.; RIVERA BEIRAS, Iñaki.; BOMBINI, Gabriel. Violencia y Sistema Penal. Buenos Aires: Editores del Puerto, Pp. 237-265.

GARCIA MAGNA, Deborah, (2019). El recurso excesivo al Derecho penal en España. Realidad y alternativas. Polít. criminal. Vol. 14, No 27 (Julio 2019), Art. 4, pp. 98-121. http://dx.doi.org/10.4067/S0718-33992019000100098

GARCIA, Elisa.; AGUILAR, Araceli.; BECERRA, José, (2013). Informe ODA. La administración de justicia según los datos. Especial referencia a la jurisdicción penal. Málaga: Instituto Andaluz Interuniversitario de Criminología. 
GARLAND, David, (2003). The Rise of Risk. In ERICSON, Richard V.; DOYLE, Aaron (eds.), Risk and Morality. Toronto: Univ. of Toronto Press.

GARLAND, David. (2005). La cultura del control. Barcelona: Gedisa.

GARRIDO GÓMEZ, María Isabel; DEL REAL ALCALÁ, Alberto, ; SOLANES CORELLA, Ángeles. (2015). Modernización y mejora de la Administración de Justicia y de la operatividad de los jueces en España. Documentos de Trabajo (IELAT, Instituto de Estudios Latinoamericanos), $\mathrm{N}^{\circ}$ 71, Pp: 1-35.

GASCÓN, Fernando, (2009). Los procesos penales en Europa: Líneas de evolución y tendencias de reforma. Revista de Derecho Procesal, 2009, Pp: 469-498.

GIMENO SENDRA, José Vicente. (2002). "Filosofía y principios de los juicios rápidos”, Diario La Ley, n 5667, Sección Doctrina, 2 de diciembre de 2002.

GIMENO SENDRA, José Vicente, (2004). La conformidad premiada en los juicios rápidos. Estudios Monográficos. La Ley Penal: Revista de Derecho Penitenciario, No 5 (mayo).

GOMÉZ COLOMER, José Luis, (2012). La conformidad, institución clave y tradicional de la justicia negociada en España. Revue Internationale de Droit Pénal. Vol.83. Pp:15-41. http://doi.org/10.3917/ridp.831.0015

GONZÁLEZ, Claudio, (2015). El New Public Management en las reformas al sistema de justicia criminal en Latinoamérica. El caso de Chile. Actas Coloquios EchFrancia. 7: 79-99.

GONZÁLEZ, Claudio, (2018). Gestión, Gerencialismo y Sistema Penal. Montevideo/ Buenos Aires: Editorial BdeF.

GONZÁLEZ, Claudio, (2020). Política Criminal y Gerencia Pública. Conceptos, características y relaciones. Revista Cuestiones Criminales. 3 (5/6). Pp: 8-34.

GRUPO DE ESTUDIOS DE POLÍTICA CRIMINAL, (2014). Una alternativa a algunas previsiones penales utilitarias. Perdón, prescripción, dilaciones indebidas y conformidad procesal. Madrid: Ed. Tirant lo Blanch y GEPC.

HARCOURT, Bernard, (2007). Against Prediction. Chicago: Univ. of Chicago Press. HARCOURT, Bernard, (2013). Política criminal y gestión de riesgos: genealogía y crítica. Buenos Aires: Ad- hoc.

HASSEMER, Winfred, ; MUÑOZ CONDE. Francisco, (1989). Introducción a la Criminología y Derecho Penal. Valencia: Tirant lo Blanc.

HERNÁNDEZ, José, (2002). Rapidez y Reformas del Proceso Penal. Jueces para la Democracia. Información y Debate 44. Pp: 27-32. 
LASCURAÍN SÁNCHEZ, Juan.Antonio.; GASCÓN INCHAUISTI, Fernando., (2018). “¿Por qué se conforman los inocentes?”, Indret, 3/2018.

LANGER, Máximo, (2007). "Revolution in Latin American criminal procedure: diffusion of legal ideas from the periphery. American Journal of Comparative Law, vol. 55. Issues 4, Pp:617-676. https://doi.org/10.1093/ajcl/55.4.617

LANGER, Máximo, (2014). La larga sombra de las categorías acusatorio-inquisitivo. Revista de Derecho Público No 32 (Universidad de los Andes). Enero-Junio. https:// doi.org/10.15425/redepub.32.2014.18

LANGER. Máximo, (2019). Plea bargaining, trial-avoiding conviction mechanisms, and the global administratization of criminal convictions. Annu. Rev. Criminol. DOI: 10.1146/annurev-criminol-032317-092255.

LOADER, Ian, ; SPARKS, Richard, (2007). Contemporary landscapes of crime, order and control: governance, risk, and globalization. In MAGUIRE, Mike et al. (eds.). The Oxford Handbook of Criminology. Oxford/New York: Oxford University Press, , 4a ed.

MARTÍNEZ, Lucía, (2014). La incertidumbre de los pronósticos de peligrosidad: consecuencias para la dogmática de las medidas de seguridad. InDret. Revista para el Análisis del Derecho. №2/2014.

MARTINEZ, Vicente, (2010). La Nueva Oficina Judicial. Revista Internauta de Práctica Jurídica. $\mathrm{N}^{\circ}$ 25. Pp: 1-17.

MOUHANNA, Christian; VESENTINI. Frédéric, (2016). Indicators or Incentives? Some Thoughts on the Use of the Penal Response Rate for Measuring the Activity of Public Prosecutors' Offices in France (1999-2010). In: HONDEGHEM, Annie.; ROUSSEAUX, Xavier.; SCHOENAERS, Fréderic. Modernisation of the Criminal Justice Chain and the Judicial System. Ius Gentium: Comparative Perspectives on Law and Justice. Vol 50. Londres: Springer.

MUERZA ESPARZA, Julio, (2015). El procedimiento monitorio penal. Actualidad Jurídica. Aranzadi No 897.

O’MALLEY, Pat, (2006). Riesgo, neoliberalismo y justicia penal. Buenos Aires: Ad-Hoc, Buenos Aires.

ORTIZ DE URBINA, Iñigo, (2003). Derecho penal orientado a las consecuencias y ciencias sociales: El análisis económico de la política criminal. Tesis doctoral. Madrid: Universidad Complutense de Madrid.

ORTIZ DE URBINA, Iñigo, (2004). Análisis económico del Derecho y Política criminal. Revista de Derecho penal y Criminología., n.o extraordinario 2. Pp: 31-73. 
PASTOR PRIETO, Santos, (2003). Dilación, eficiencia y costes. ¿cómo ayudar a que la imagen de la Justicia se corresponda mejor con la realidad?. Working Papers 201010, Fundación BBVA/BBVA.

PASTOR PRIETO, Santos, (1989). Sistema jurídico y economía. Una introducción al análisis económico del Derecho. Madrid: Ed. Tecnos.

PUEYO, Andrés. ; REDONDO, Santiago, (2007). Predicción de la violencia: Entre la peligrosidad y la valoración del riesgo de violencia. Papeles del Psicólogo, 28(3), 157-173.

RAYON BALLESTEROS, María, (2007). La nueva oficina judicial para el siglo XXI. Anuario Jurídico y Económico Escurialense, XL (2007) 303-322.

RIVERA-BEIRAS, Iñaki, (2015). Actuarialismo penitenciario. Su recepción en España. Revista Crítica Penal y Poder, No 9. Pp:102-144. Observatorio del Sistema Penal y los Derechos Humanos Universidad de Barcelona.

SCHÜNEMANN, Bernard, (2002). ¿Crisis del procedimiento penal?. Marcha triunfal del procedimiento penal americano en el mundo. En "Temas actuales y permanentes del Derecho penal después del milenio”. Madrid: Tecnos.

SILVA SÁNCHEZ, Jesús, (2006). La expansión del Derecho penal. Aspectos de la política criminal en las sociedades postindustriales. Buenos Aires-Montevideo: BdeF.

SILVA SÁNCHEZ, Jesús, (1996) «Eficiencia y Derecho Penal», en ADPCP, pp. 93-127.

SIMON, Jonathan, (1988). The Ideological Effects of Actuarial Practices, en Law and Society Review, vol. 22, No. 4, 1988, Pp: 771 y ss. https://doi.org/10.2307/3053709 SOZZO, Máximo, (2020). Reforma de la justicia penal en América Latina. Promesas, prácticas y efectos. Buenos Aires: Ediciones DIDOT.

TURNER, Jenia, (2017). Plea Bargaining and International Criminal Justice. The University of the Pacific Law Review, Vol. 48, 2017.

VIANO, Emilio, (2012). Plea bargaining in the United States: A perversion of Justice Revue International de Droit Penal, vol. 83. Pp: 109-145. https://doi.org/10.3917/ ridp.831.0109

VIGOUR, Cécile, (2006). Justice: L'introduction d'une rationalité managériale comme euphémisation des enjeux politiques. Droit et Société, No. 63-64, Pp: 425-455. https://doi.org/10.3917/drs.063.0425

VILA, David, (2013). Regímenes de valoración de riesgos en las políticas de seguridad y control contemporáneas. Revista electrónica de Ciencia penal y Criminología. No $15-10$. 
VILLEGAS, Jesús, (2010). El Informe Léger: La supresión del juez instructor francés. Revista Internauta de Práctica Jurídica. Núm. 25, Pp. 19-35.

WEIGEND, Thomas. (2021). exclusion without trial? exclusion of evidence and abbreviated procedures. Revista Brasileira de Direito Processual Penal, Porto Alegre, vol. 7, n. 1, p. 247-271, jan./abr. https://doi.org/10.22197/rbdpp.v7i1.502

\section{Additional information and author's declarations (scientific integrity)}

Acknowledgement: Este artículo es fruto de la estancia de investigación del autor en el Instituto de Criminología de la Universidad de Málaga el año 2020, y constituye parte de su proyecto de investigación Fondecyt/Posdoctoral No 3180458 financiado por la Agencia Nacional de Investigación y Desarrollo de Chile (ANID), proyecto denominado "Análisis del concepto y uso de la eficiencia en el sistema penal chileno: El factor cuantitativo-gerencial”. También agradezco a los profesores F. Montijano, J. Becerra y J. Orellana del departamento de Derecho penal de la Universidad de Málaga, y al profesor J.A, Brandariz de la Universidade da Coruña, por sus valiosas sugerencias y críticas al borrador de este texto.

Conflict of interest declaration: the author confirms that there are no conflicts of interest in conducting this research and writing this article.

Declaration of authorship: all and only researchers who comply the authorship requirements of this article are listed as authors; all coauthors are fully responsible for this work in its entirety.

Declaration of originality: the author assures that the text here published has not been previously published in any other resource and that future republication will only take place with the express indication of the reference of this original publication; he also attests that there is no third party plagiarism or self-plagiarism. 


\section{Editorial process dates}

(http://www.ibraspp.com.br/revista/index.php/RBDPP/about/editorialPolicies)

- Submission: 27/04/2021

- Desk review and plagiarism check: 27/04/2021

- Review 1: 09/05/2021

- Review 2: 09/05/2021

- Preliminary editorial decision and transference to V7N3: 16/05/2021

- Correction round return: 24/05/2021

- Final editorial decision: 30/05/2021

- Postprint deposit: 25/06/2021 https://doi. org/10.1590/SciELOPreprints.2515

\section{HOW TO CITE (ABNT BRAZIL):}

GONZÁLEZ GUARDA, Claudio Javier. La eficiencia en el sistema penal español: con especial referencia al modelo de conformidades.

Revista Brasileira de Direito Processual Penal, vol. 7, n. 3, p. 2061-2102, set./dez. 2021. https://doi.org/10.22197/rbdpp.v7i3.538

\section{Editorial team}

- Editor-in-chief: 1 (VGV)

- Reviewers: 2 